\title{
Optical Properties and Applications of Silicon Carbide in Astrophysics
}

\author{
Karly M. Pitman ${ }^{1}$, Angela K. Speck², \\ Anne M. Hofmeister ${ }^{3}$ and Adrian B. Corman ${ }^{3}$ \\ 1 Planetary Science Institute \\ ${ }^{2}$ Dept. of Physics $\mathcal{E}$ Astronomy, University of Missouri-Columbia \\ ${ }^{3}$ Dept. of Earth $\mathcal{E}$ Planetary Sciences, Washington University in St. Louis
}

USA

\section{Introduction}

Optical properties, namely, spectra and optical functions, of silicon carbide $(\mathrm{SiC})$ have been of great interest to astrophysicists since $\mathrm{SiC}$ was first theoretically posited to exist as dust, i.e., submicron-sized solid state particles, in carbon-rich circumstellar regions (Gilman, 1969; Friedemann, 1969). The prediction that $\mathrm{SiC}$ in space should re-emit absorbed radiation as a spectral feature in the $\lambda=10-13 \mu \mathrm{m}$ wavelength region (Gilra, 1971, 1972) was confirmed by a broad emission feature at $\lambda \sim 11.4 \mu \mathrm{m}$ in the spectra of several carbon-rich stars (Hackwell, 1972; Treffers \& Cohen, 1974). Many carbon-rich, evolved stars exhibit the $\lambda \sim 11 \mu \mathrm{m}$ feature in emission, and $\mathrm{SiC}$ is now believed to be a significant constituent around them (Speck, 1998; Speck et al., 2009 and references therein).

\subsection{Role of SiC in stellar environments}

Detection of $\mathrm{SiC}$ in space provides much information on circumstellar environments because the chemical composition and structure of dust in space is correlated with, e.g., the pressure, temperature, and ratios of available elements in gas around stars. The mere presence of $\mathrm{SiC}$ implies that the carbon-to-oxygen (C/O) must be high. Different polytypes of SiC identify the temperature and gas pressure within the dust forming region around a star. The significance of $\mathrm{SiC}$ in stars is tied intimately to stellar evolution, as dust grains participate in feedback relationships between stars and their circumstellar envelopes that affect mass-loss rates, i.e., stellar lifetimes. Meteoritic $\mathrm{SiC}$ grains exhibit signatures of s-process enrichment, one of the main attributes of the evolutionary track of carbon-rich stars.

\subsubsection{S-process isotopic signatures in SiC}

Elements more massive than helium have been formed in stars. All elements $>{ }^{56} \mathrm{Fe}$ are generated by neutron capture because there is no Coulomb barrier for adding a neutral particle. In the s-process (slow neutron capture), neutrons are added to atomic nuclei slowly as compared to the rate of beta decay (cf. Burbidge, et al. 1957, a.k.a., B2FH; Cameron 1957). The precise isotopes of heavy elements depend on the rate of neutron capture, which, in turn, is strongly dependent on the properties of the stellar sources. Thus, it is possible to 
uniquely identify different masses or types of stars as the sources of isotopically non-solar dust grains. $\mathrm{SiC}$ was the first meteoritic dust grain to be discovered that, on the basis of its isotopic composition, obviously formed before and survived the formation of the solar system (Bernatowicz et al., 1987). Further studies of the precise isotopic compositions of these meteoritic "presolar" grains have identified their stellar sources. For SiC, 99\% of the presolar grains are characterized by high abundances of s-process elements, indicative of formation around certain classes of evolved, intermediate mass stars (described below).

\subsubsection{Space environments containing SiC}

Figure 1 illustrates the varied space environments in which $\mathrm{SiC}$ has been detected. To understand the nature of $\mathrm{SiC}$ in these environments and how $\mathrm{SiC}$ originally formed in the universe, Figure 2 and the following text describe how these categories of stars evolve.

\subsubsection{Asymptotic Giant Branch (AGB) stars}

Figure 2 illustrates the evolution of low-to-intermediate-mass stars (LIMS; 0.8-8 times the mass of the Sun, $\left.\mathrm{M}_{\odot}=1.98892 \times 10^{30} \mathrm{~kg}\right)$. In the late stages of evolution, LIMS follow a path up the Asymptotic Giant Branch (AGB; Iben \& Renzini, 1983). During the AGB phase, stars are very luminous $\left(\sim 10^{3}-10^{4} \mathrm{~L}_{\odot}\right.$, where $\left.\mathrm{L}_{\odot}=3.839 \times 10^{33} \mathrm{erg} / \mathrm{s}\right)$ and large $\left(\sim 300 \mathrm{R}_{\odot}\right.$, where $\mathrm{R}_{\odot}=$ $\left.6.995 \times 10^{8} \mathrm{~m}\right)$ but have relatively low surface temperature $(\sim 3000 \mathrm{~K})$. AGB stars pulsate due to dynamical instabilities, leading to intensive mass loss and the formation of circumstellar shells of gas and dust. The carbon-to-oxygen ratio $(\mathrm{C} / \mathrm{O})$ controls the chemistry around the star: whichever element is less abundant will be entirely locked into $\mathrm{CO}$ molecules, leaving the more abundant element to control dust formation. Therefore, AGB stars can be either oxygenrich or carbon-rich. Approximately $1 / 3$ of AGB stars are C-rich (i.e., C/O > 1). Whereas Cstars are expected to have circumstellar shells dominated by amorphous or graphitic carbon, $\mathrm{SiC}$ is also expected to form; its IR spectrum provides a diagnostic tool not available from the carbonaceous grains. Therefore, $\mathrm{SiC}$ has been of greatest interest to astrophysicists seeking to understand the evolution of dust shells and infrared features of C-stars (Baron et al., 1987; Chan \& Kwok, 1990; Goebel et al., 1995; Speck et al., 1997; Sloan et al., 1998; Speck et al., 2005, 2006; Thompson et al., 2006). For Galactic sources, the majority of C-stars should first condense $\mathrm{TiC}$, then $\mathrm{C}$, then $\mathrm{SiC}$, as supported by meteoritic evidence (e.g., Bernatowicz et al., 2005). As C-stars evolve, mass loss is expected to increase. Consequently, their circumstellar shells become progressively more optically thick, and eventually the central star is obscured. Volk et al. (1992, 2000) christened such stars "extreme carbon stars" (e.g., Fig. 1a). Extreme carbon stars are expected to represent that small subset of C-rich AGB stars just prior to leaving the AGB. Because that phase is short-lived, the number of extreme C-stars is intrinsically small and few of these objects have been found in space ( $\sim 30$ known in the Galaxy: Volk et al., 1992, versus $\sim 30,000$ known visible C-stars: Skrutskie et al., 2001).

\subsubsection{Post-AGB stars}

Once the AGB phase ends, mass loss virtually stops, and the circumstellar shell begins to drift away from the star. At the same time, the central star begins to shrink and heat up from $\mathrm{T}=$ $3000 \mathrm{~K}$ until it is hot enough to ionize the surrounding gas, at which point the object becomes a planetary nebula (PN; e.g., Fig. 1c). The short-lived post-AGB phase, as the star evolves toward the PN phase, is also known as the proto- or pre-planetary nebula (PPN) phase (e.g., Fig. 1b). As the detached dust shell drifts away from the central star, the dust cools, causing a PPN to have cool infrared colors. Meanwhile, the optical depth of the dust shell decreases, 
allowing the central star to be seen and making such objects optically bright. The effect of decreasing optical depth and cooling dust temperatures changes the appearance of the circumstellar envelope, revealing features that were hidden during the AGB phase.

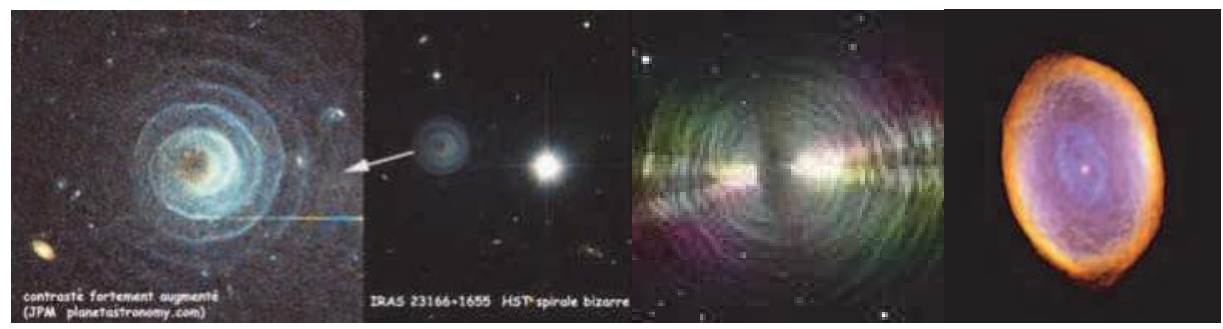

Fig. 1. Astronomical objects in which SiC has been detected. Left to right: (a) Hubble Space Telescope image of the extreme carbon star AFGL 3068. Source: Mauron \& Huggins (2006); http:/ / www.planetastronomy.com (b) The Egg Nebula, illustrating polarization through a thick vertical dust belt in the center of a pre- or proto-planetary nebula. Source: NASA and The Hubble Heritage Team (STScI/ AURA); W. Sparks (STScI), R. Sahai (JPL);

http:/ / heritage.stsci.edu (c) IC 418, the Spirograph Nebula, is one of only a handful of galactic planetary nebulae that actually show SiC emission. Source: NASA and The Hubble Heritage Team (STScI/AURA); R. Sahai (JPL), A. Hajian (USNO); http:/ / hubblesite.org

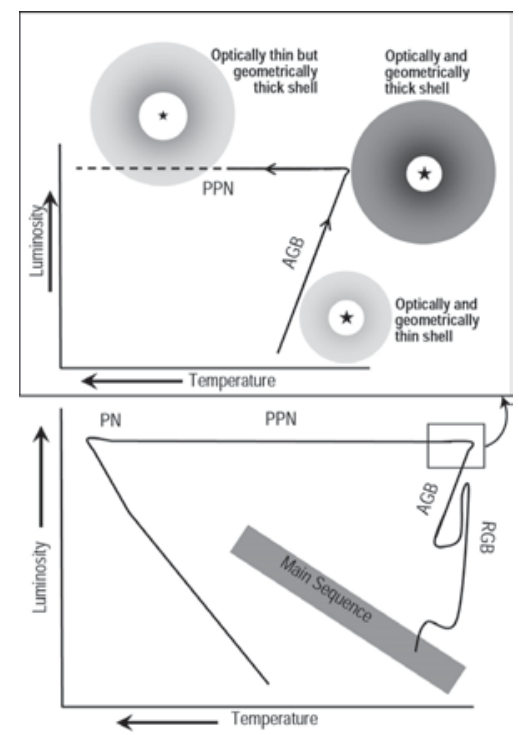

Fig. 2. Schematic diagram of the evolution of low-to-intermediate-mass stars. Bottom: A $1 \mathrm{M}_{\odot}$ star begins its life on the main sequence, converting $\mathrm{H}$ into $\mathrm{He}$ in its core; when $\mathrm{H}$ is depleted, it exits to the Red Giant Branch (RGB), then the Asymptotic Giant Branch (AGB), where $\mathrm{SiC}$ formation occurs. Top: During the AGB phase, the dust shell get thicker and stars become very bright in the IR. Intense mass loss depletes the remaining $\mathrm{H}$ in the star's outer envelope in a few $\times 10^{4}$ years (Volk et al., 2000) and terminates the AGB phase. Stars may then become proto-planetary nebulae (PPN), or later planetary nebulae (PN). 
Infrared (IR) spectroscopy is used to probe the nature of $\mathrm{SiC}$ dust grains in space because dust particles of a given size, shape, temperature, structure, and composition have their own signature IR spectrum. Dust grains absorb high energy photons from stars and re-emit in the IR, in accordance with the specific (low) temperatures of any given grain. Therefore, to account for the energy budget in astronomical environments, astrophysicists are also interested in how $\mathrm{SiC}$ dust grains absorb and scatter UV-vis photons, which requires knowledge of $\mathrm{SiC}$ optical functions. Lines of evidence or constraints that astrophysicists use to aid studies of $\mathrm{SiC}$ dust in space include evidence from meteoritic studies, comparisons between the positions and shapes of spectral features for astronomical objects and laboratory analogue materials, spatial distributions of materials, and theoretical models for dust formation.

\section{Silicon carbide in meteorites}

$\mathrm{SiC}$ particles were the first presolar dust grains found in meteorites (Bernatowicz et al., 1987) and remain the best studied (e.g. Clayton \& Nittler, 2004; Bernatowicz et al., 2006; Hoppe, 2009). Presolar grains are ancient refractory dust with the isotopic makeup of stars that exist as individual particles or clusters found in the matrix, or fine-grained crystalline mass, of a meteorite. Ages of meteoritic $\mathrm{SiC}$ grains are discussed by Ott (2010). Figure 3 describes the family of meteorite classes that contain presolar $\mathrm{SiC}$ grains. The most studied meteorites that contain presolar $\mathrm{SiC}$ are carbonaceous chondrites (e.g., the class CM2 Murchison and Murray meteorites, classes CI1 = Orgueil, CV3 = Allende) which are considered to be the most primitive or least processed solid materials in the Solar System. Presolar SiC is also found in other stony meteorite types as well: enstatite chondrites (e.g., EH4 = Indarch, EH3 = Qingzhen) and ordinary chondrites (e.g., H/L 3.6 = Tieschitz, LL 3.1 = Bishunpur, Krymka, LL $3.5=$ Chainpur, L/LL $3.4=$ Inman; LL 3.0 = Semarkona). Investigations via scanning and transmission electron microscopy have revealed the physical morphology of presolar SiC grains (Figure 4). Whereas presolar grains are rare (Clayton \& Nittler, 2004) and very small (typically less than $1 \mu \mathrm{m}$ in size: Amari et al., 1994), presolar SiC grains are more abundant than other presolar compositions (up to $30 \mathrm{ppm}$ in the Murchison meteorite: Ott \& Merchel, 2000) and, at $1.5 \mathrm{~nm}$ to $26 \mu \mathrm{m}$ in size, many are large enough to be probed for their isotopic composition (Yin et al., 2006; Speck et al. 2009, and references therein).

As discussed in the introduction, $\mathrm{SiC}$ presolar grains are identified by their anomalous isotopic compositions. In fact, their isotopic compositions have not only identified their likely cosmic sources, but also have provided key tests of hypotheses for nucleosynthesis (element creation) and generate the data needed to refine those hypotheses. Whereas $\sim 1 \%$ of presolar SiC probably emanates from stellar environments such as novae and supernovae, the vast majority have isotopic compositions consistent with formation around AGB stars. Because the s-process is the dominant method of forming heavy elements in AGB stars, the $\mathrm{SiC}$ grains that form within AGB stellar envelopes are excellent tracers of unadulterated sprocess isotopes. Studies of these presolar grains are used to determine s-process timescales, stellar temperature and masses, and neutron exposure rates of stellar nuclei.

Compared to solar isotopes, presolar $\mathrm{SiC}$ grains exhibit anomalous isotopic compositions for their major components $\mathrm{C}$ and $\mathrm{Si}$, as well as trace elements: $\mathrm{N}, \mathrm{Mg}, \mathrm{Ca}, \mathrm{Ti}, \mathrm{Sr}, \mathrm{Zr}, \mathrm{Mo}, \mathrm{Ba}$, $\mathrm{Nd}, \mathrm{Sm}, \mathrm{Dy}$, and the noble gases (Hoppe \& Ott, 1997). Based on such isotopic analyses, six types of presolar $\mathrm{SiC}$ have been established according to their $\mathrm{Si},{ }^{12} \mathrm{C} /{ }^{13} \mathrm{C},{ }^{14} \mathrm{~N} /{ }^{15} \mathrm{~N}$, and ${ }^{26} \mathrm{Al} /{ }^{27} \mathrm{Al}$ ratios (e.g., table 2, Ott, 2010 and references therein): "mainstream" SiC, versus 
types A, B, X, Y, and Z. The "mainstream" SiC population, constituting 87-94\% of known presolar $\mathrm{SiC}$ grains, is believed to have originated around C-rich AGB stars. Compared to "mainstream" $\mathrm{SiC}$, A and B SiC grains have low ${ }^{12} \mathrm{C} /{ }^{13} \mathrm{C}$ but a similar Si profile; they are thought to derive from a particular class of $\mathrm{C}$-star. $\mathrm{Y}$ and $\mathrm{Z} \mathrm{SiC}$ grains are typically small as compared to other presolar SiC grains, are easily distinguished from the "mainstream" class by their Si content, and come from either low mass, low metallicity AGB stars that undergo different types of processing or possibly novae. Type $X \mathrm{SiC}$ grains are the most rare $(\sim 1 \%$ of presolar $\mathrm{SiC}$ ), are generally collections of many $<100 \mathrm{~nm}$-sized rather than individual grains, and have been posited to derive from ejecta of core-collapse (Type II) supernovae.

Laboratory studies of presolar meteoritic $\mathrm{SiC}$ grains have utilized and developed many innovative techniques (see review by Hoppe, 2009). Initial works relied on ion microprobe and secondary ion mass spectrometry (SIMS) techniques to determine isotopic compositions for light and intermediate mass elements in individual presolar $\mathrm{SiC}$ grains, including $\mathrm{C}, \mathrm{N}$, $\mathrm{Si}$, Ca, Ti, Mg, Al, O, V, Fe, Sr, Y, Zr, Nb, Ba, Ce, Nd, B (Amari et al., 1992, 1995, 1996, 1997a, 1997b; Hoppe et al. 1994a, 1994b, 1996, 2000, 2001). Post 2001, efforts to drive down the diameter of the primary ion beam and thus be able to probe presolar grains smaller than 0.5 $\mu \mathrm{m}$ resulted in a series of studies using the Cameca NanoSIMS 50 ion microprobe (Besmehn \& Hoppe, 2002; Hoppe \& Besmehn, 2002; Gyngard, 2009). Time-of-flight secondary ion mass spectrometry (TOF-SIMS) has been applied to submicron presolar SiC grains in an effort to sputter less sample (Henkel et al., 2007), and atomic probe tomography (field ion microscope + TOF mass spectrometer) has also been tested on presolar and synthetic SiC grains to significantly improve upon the spatial resolution of NanoSIMS (Heck et al., 2010). Resonance ion mass spectrometry (RIMS) studies have further quantified the isotopic compositions of heavy elements such as $\mathrm{Zr}$, Mo, and $\mathrm{Ba}$ in presolar SiC grains (e.g., Nicolussi et al., 1997, 1998; Savina et al., 2003; Barzyk, 2007). Laser heating experiments by Nichols et al. (1992) and later work by Heck (2005) have yielded the isotopic compositions of $\mathrm{He}$ and Ne in presolar SiC. Combinations of SIMS, RIMS, gas mass spectrometry, and other experimental methods (e.g., SEM, TEM, Auger spectroscopy) are currently being employed in analyses of presolar SiC grains (cf. Stroud et al., 2004).

A subset of studies on the isotopic compositions of presolar $\mathrm{SiC}$ grains investigates the effect of grain sizes on concentrations of s-process elements. Prombo et al. (1993) found a correlation between grain size and the concentration of s-process elements in the presolar $\mathrm{SiC}$ grains taken from the Murchison meteorites. Presolar SiC grains from the Indarch meteorite yielded similar results (Jennings et al., 2002). In both cases, the smaller grains have higher relative abundances of s-process elements.

In addition to the isotopic studies of presolar $\mathrm{SiC}$, crystallographic studies have shown that nearly all are of the $\beta$-polytype (cubic crystal structure) and the $6 \mathrm{H}$ - $\alpha$-polytype is never found. In the Murray C2 carbonaceous chondritic meteorite in which presolar SiC was first unequivocally detected, cubic and $\{111\}$-twinned cubic were the most common structural forms (Bernatowicz et al. 1987, 1988a, 1988b). Daulton et al. $(2002,2003)$ itemize the amount of $3 \mathrm{C} \beta-\mathrm{SiC}(80 \%), 2 \mathrm{H}$ a-SiC $(3 \%)$, and intergrowths of these two forms $(17 \%)$ present in presolar $\mathrm{SiC}$ grains. This is significant in astrophysics because which polytype of $\mathrm{SiC}$ forms in space strongly depends on the temperature and gas pressure within the dust-forming region. $2 \mathrm{H}$ and $3 \mathrm{C}$ are the polytypes that form at the lowest temperature where $\mathrm{SiC}$ condenses; which of $2 \mathrm{H}$ or $3 \mathrm{C} \mathrm{SiC}$ forms depends on many factors, such as $\mathrm{Si} / \mathrm{C}$ ratio.

For further reviews of $\mathrm{SiC}$ and cosmic dust in meteorites, see also Anders \& Zinner (1993), Hoppe \& Ott (1997), Hoppe \& Zinner (2000), Hoppe (2009), Ott (2010), and Henning (2010). 


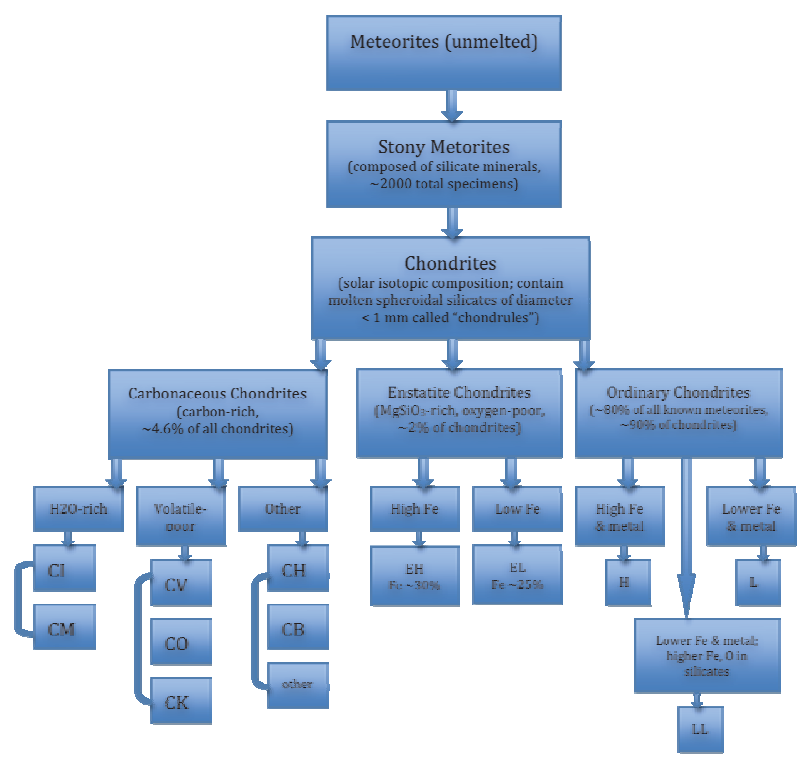

Fig. 3. Meteorite classification formalism, adapted from The Natural History Museum, London (http:// www.nhm.ac.uk). Presolar $\mathrm{SiC}$ grains are dominantly found in the carbonaceous chondrite classes $\mathrm{CM}, \mathrm{CI}$, and $\mathrm{CV}$, but occur over a range of subclasses. The numbers (e.g., the "2" in "CM2") represent the petrologic grade of the meteorite (Van Schmus \& Wood, 1967); " 1 " or " 2 " refers to the degree of hydration or aqueous alteration, whereas for a value of 3 or greater, higher numbers imply successively higher degrees of thermal metamorphism.
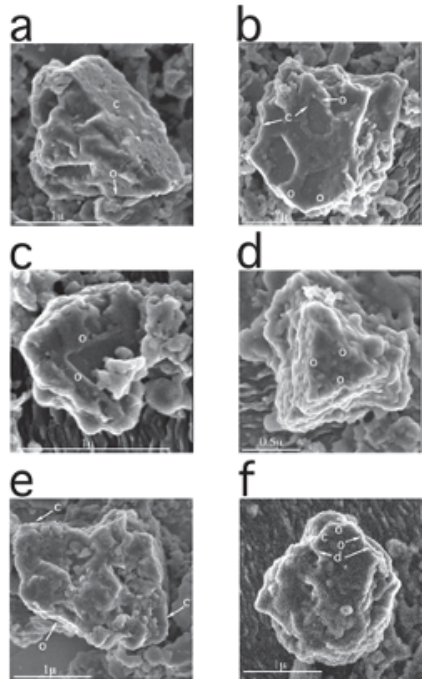

Fig. 4. Microscopy images of pristine presolar SiC grains, courtesy of T. Bernatowicz. Scale bar $=1 \mu \mathrm{m}$ for all images except panel $(\mathrm{d})=0.5 \mu \mathrm{m}$. 


\section{Laboratory astrophysics of silicon carbide}

For $\mathrm{SiC}$, the major spectral features result from cation-anion charge transfer and/or electronic band gap transitions in the visible-UV, as well as from lattice vibrations in the IR. Vibrational motions involving a change in the dipole moment are IR active. The nearest-neighbor interaction between $\mathrm{Si}$ and $\mathrm{C}$ produces a strong band in the IR, regardless of polytype. The stacking disorder that exists for SiC lowers crystal symmetry, resulting in vibrational transitions that increase in number with polytype complexity. For all polytypes of $\mathrm{SiC}$, the transverse optic mode (TO) is present at $\sim 12.5 \mu \mathrm{m}$ and the longitudinal optic mode (LO) is seen at $10.3 \mu \mathrm{m}$ (Nakashima \& Harima, 1997). Electronic transitions occur throughout the visible-UV and are strongest at $\sim 0.111 \mu \mathrm{m}$ (Philipp \& Taft, 1960). Laboratory astrophysics studies focus on low energy or IR wavelength $\mathrm{SiC}$ spectral features (at $\lambda \sim 11 \mu \mathrm{m}, 21 \mu \mathrm{m}$ ) to identify cosmic SiC in space, and also quantify the optical depth of and chemical impurities or defects in cosmic SiC via the general spectral behavior of the UV.

\subsection{Spectroscopic studies: Ultraviolet and infrared}

Past laboratory spectral studies utilized by astrophysicists are published across multiple disciplines. Although UV measurements for other sample types, e.g., extinction of light from SiC smoke particles (Stephens, 1980), have also been used in astrophysics, this paragraph reviews the state of single-crystal $\mathrm{SiC}$ spectroscopic studies in the UV and gives examples of UV SiC spectra in Figures 5 and 6. The polytypes that matter most to astrophysicists are 3C, $2 \mathrm{H}$, and $4 \mathrm{H}$, on the basis of the meteoritic record; data on other forms (e.g., $8 \mathrm{H}, 15 \mathrm{R}, 21 \mathrm{R}$ ) have not been considered. Because the $6 \mathrm{H}$ form of $\mathrm{a}-\mathrm{SiC}$ is available commercially with large faces perpendicular to $\mathrm{c}$ axis, for which unpolarized measurements provide data on $\mathrm{E}$ $\perp \mathrm{c}$, there is a wealth of laboratory spectra on $6 \mathrm{H}$ in this orientation. The first a-SiC laboratory reflectance data (e.g., Philipp, 1958; Wheeler, 1966) were gathered at resolutions lower by at least a factor of two than can be attained with modern instrumentation. In the ultraviolet, modern commercial instruments exist and are inexpensive for wavelengths down to $0.192 \mu \mathrm{m}$ (or, for a factor of $\times 10$ more in cost, down to $0.164 \mu \mathrm{m}$, the "vacuum UV"). However, spectral data for $\mathrm{SiC}$ used by astrophysicists does not extend much past $200 \mathrm{~nm}$, as summarized in Figure 5. Early works on UV SiC spectroscopy studied in the astrophysics literature include Choyke \& Patrick (1957), Philipp (1958), and Philipp \& Taft (1960). Choyke \& Patrick (1957) measured transmission (converted to absorption coefficient in $\mathrm{cm}^{-1}$ ) for one $\alpha$-SiC plate, whereas Philipp (1958) measured absorption for yellow 3C and colorless $6 \mathrm{H} \mathrm{SiC} \mathrm{single} \mathrm{crystal} \mathrm{samples} \mathrm{of} \mathrm{varying} \mathrm{thicknesses.} \mathrm{In} \mathrm{both} \mathrm{studies,} \mathrm{samples} \mathrm{were} \mathrm{not} \mathrm{well}$ characterized in terms of SiC impurities, stacking faults, and defects, which are highly important in the UV-vis. Philipp \& Taft (1960) presented reflectance spectra from $\sim 0.11$ to $0.62 \mu \mathrm{m}$ for hexagonal $\mathrm{SiC}$. Because reliable reflectivity standards were not available at that time, uncertainties in absolute $\mathrm{R}$ were large (i.e., > 5\%). Hofmeister et al. (2009) published new data on the visible to soft UV range $(1.11-0.303 \mu \mathrm{m})$ for $\alpha$ - and $\beta$-SiC single crystals with emphasis on impurities. In that study, absorbance spectra were provided for $6 \mathrm{H}$ and $3 \mathrm{C} \mathrm{SiC}$ ( $\mathrm{E}|| \mathrm{c}$ and $\mathrm{E} \perp \mathrm{c}$ ) as electronic tables for $\lambda=2.5-16.36 \mu \mathrm{m}$; figure 7 of that work provides absorbance spectra shortward of $2.5 \mu \mathrm{m}$. Additional laboratory UV absorption spectra (e.g., Choyke \& Patrick 1968, 1969) and reflectivity spectra, including experimentally measured and calculated data (Wheeler, 1966; Belle et al., 1967; Lubinsky et al., 1975; Rehn et al., 1976; Gavrilenko, 1995; Logothetidis \& Petalas, 1996; Adolph et al., 1997; Gavrilenko \& Bechstedt, 
1997; Theodorou et al., 1999; Ismail \& Abu-Safia, 2002; Xie et al., 2003; Lindquist et al., 2004) that extend into the vacuum UV are available in the semiconductor literature. In particular, the effect of SiC polytype on reflectivity was discussed by Lambrecht et al. (1993, 1994, 1997); we note that the reflectivity values from Lambrecht et al. (1997) are too low by $20 \%$, caused by calibrating against a low value of real index of refraction $(n=2.65)$ at $\sim 0.31 \mu \mathrm{m}$ (e.g., Petalas et al., 1998). The spectroscopic ellipsometry study by Petalas et al. (1998) provides reflectivity in agreement with Philipp \& Taft (1960) and Wheeler (1966). The reflectivity data by Wheeler (1966) have been used extensively in comparison in the physics and materials literature but show structure on the spectral peaks that may not be real since those features were not observed subsequently; thus, those data are not shown explicitly in Figure 5. For further discussion, see the review by Devaty \& Choyke (1997).
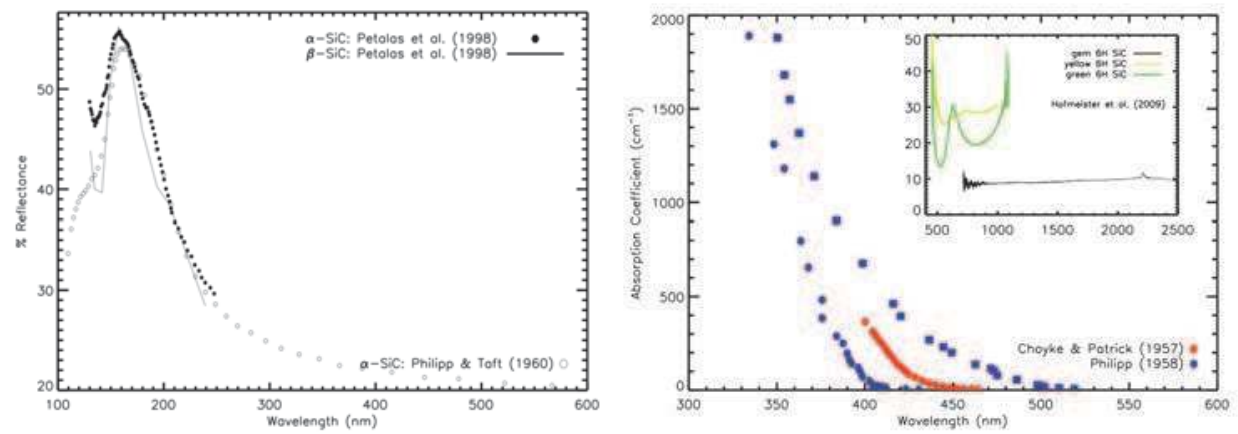

Fig. 5. UV-visible reflectance spectra and absorption coefficients. $1 \mathrm{~nm}=10^{-3} \mu \mathrm{m}$. Panel (a): Open symbols: Philipp \& Taft (1960), solid symbols and line: Petalas et al. (1998). Panel (b): Squares $=3 \mathrm{C} \mathrm{SiC}$, hexagons $=6 \mathrm{H} \mathrm{SiC}$. Inset: gem $6 \mathrm{H} \mathrm{SiC}=$ synthetic moissanite.

In the infrared, many laboratory studies of $\mathrm{SiC}$ are available in astrophysics, some of which should be compared to semiconductor-relevant data with care. Spitzer et al. (1959a) obtained reflectivity data from a thin $(0.06 \mu \mathrm{m})$ film of $\beta$-SiC that was vapor-deposited on a Si surface. Spitzer et al. (1959b) provided laboratory data for both polarizations of $6 \mathrm{H}$ single-crystals. Another widely cited source in astrophysics is the a-SiC $\mathrm{E} \perp \mathrm{c}$ data shown in figure 9.6 of Bohren \& Huffman (1983); that work did not provide experimental details, such as which polytype of a-SiC was used. Mutschke et al. (1999) presented averages of spectral parameters from many experimental studies of $\mathrm{SiC}$ from the 1960 's to 1990 's to obtain TO frequency positions, LO frequency positions or oscillator strengths, and full width at half maximum values for $\mathrm{SiC}$. Other published works on SiC from astrophysics (e.g., Friedemann et al., 1981; Borghesi et al., 1985; Orofino et al., 1991; Papoular et al., 1998; Mutschke et al., 1999; Andersen et al., 1999, and references therein) are predominantly laboratory absorbance studies of powder samples, embedded in a (usually $\mathrm{KBr}$ ) matrix. Strong differences in the spectra and optical properties obtained from powders (cf. Huffman, 1988; Mutschke et al., 1999) can be attributed to variations in clustering of grains, dilution, mean and distributions of grain size and shape. Laser pyrolysis has also been used to produce $\mathrm{SiC}$ particles most closely resembling those found in stellar environments (cf. Willacy \& Cherchneff, 1998; Mutschke et al., 1999). Because the laser pyrolysis SiC samples are not of the order of several $\mathrm{mm}$ in diameter (cf. Hofmeister et al., 2003), those 
measurements should not be used for determining bulk optical functions. A wavelength shift (the KBr matrix correction, cf. Friedemann et al., 1981) has been applied to some laboratory spectra of sub- $\mu \mathrm{m} \mathrm{SiC} \mathrm{grains} \mathrm{dispersed} \mathrm{in} \mathrm{single-crystal} \mathrm{matrices.} \mathrm{Studies} \mathrm{of} \mathrm{thin}$ films and isolated nanoparticles of $\beta$-SiC have shown that this wavelength shift is unnecessary when measurements are made carefully (Speck et al., 1999; Clément et al., 2003). Past astrophysical studies were also divided on whether the crystal structure of SiC can be determined from IR spectra (in favor: Borghesi et al., 1985; Speck et al., 1999; opposed: Spitzer et al., 1959a, 1959b; Papoular et al., 1998; Andersen et al., 1999; Mutschke et al., 1999). Pitman et al. (2008) showed that spectroscopic differences exist between a-SiC E | | c, versus $\beta$-SiC or $a-S i C ~(E \perp c)$. Pitman et al. (2008) provided electronic mid- and far-IR room temperature reflectance spectra of thin film $6 \mathrm{H} \mathrm{SiC} \mathrm{(two} \mathrm{orientations,} \mathrm{several} \mathrm{varieties)}$ and semiconductor grade purity $3 \mathrm{C} \mathrm{SiC}$.

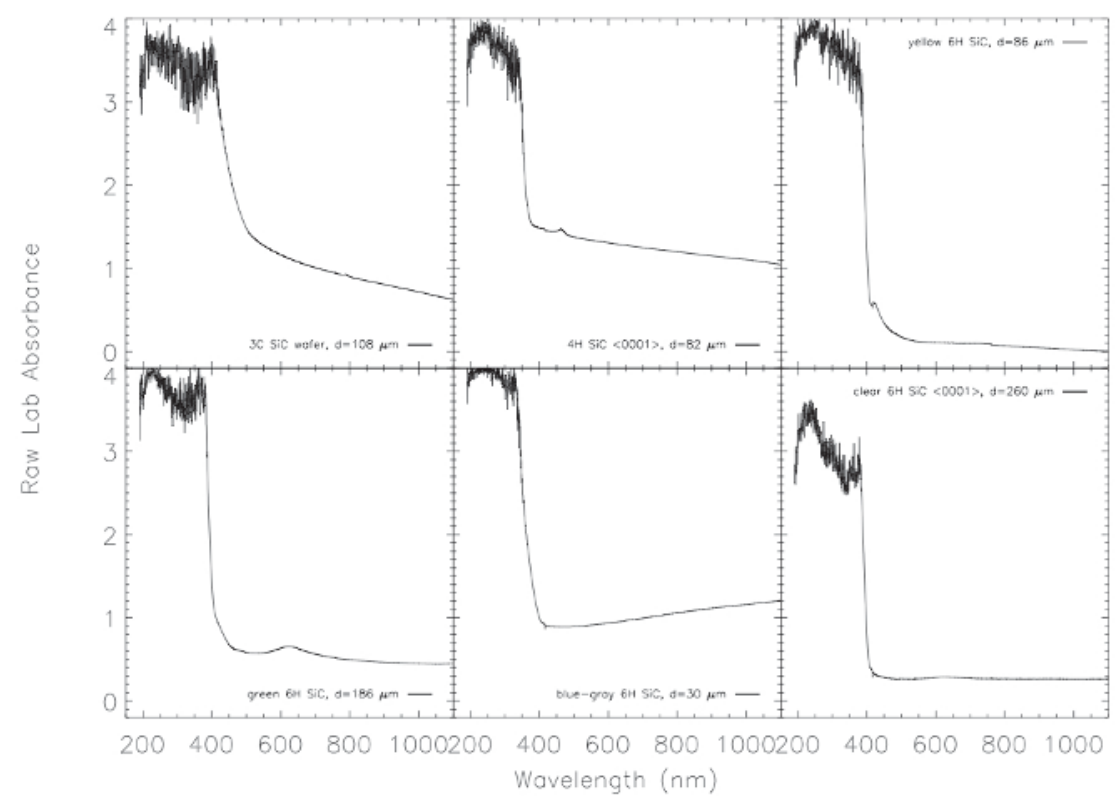

Fig. 6. Comparing the effects of color impurities and polytype of $\mathrm{SiC}$ in the UV-vis. $1 \mathrm{~nm}=$ $10^{-3} \mu \mathrm{m} . \mathrm{d}=$ thickness of sample. Vertical axis given in common log absorbance.

The two SiC spectral features of greatest interest to astrophysicists are at 11 and $21 \mu \mathrm{m}$. The utility of the $11 \mu \mathrm{m}$ feature (shown in Figure 7) will be discussed in Section 4. Among the Crich post-AGB stars (PPNe), approximately half exhibit a feature in their infrared spectra at $21 \mu \mathrm{m}$. This enigmatic feature has been widely discussed since its discovery (Kwok et al., 1989) and has been attributed to both transient molecular and long-lived solid-state species, but most of these species have been discarded. The most promising carrier is SiC (Speck \& Hofmeister, 2004), on the basis of lab spectroscopy (Figure 8). The peak positions and profile shapes of the $21 \mu \mathrm{m}$ band are remarkably constant, both in space (Volk et al., 1999) and in laboratory SiC spectra (Table 1). Kimura et al. (2005a, 2005b) produced nano-diamond 

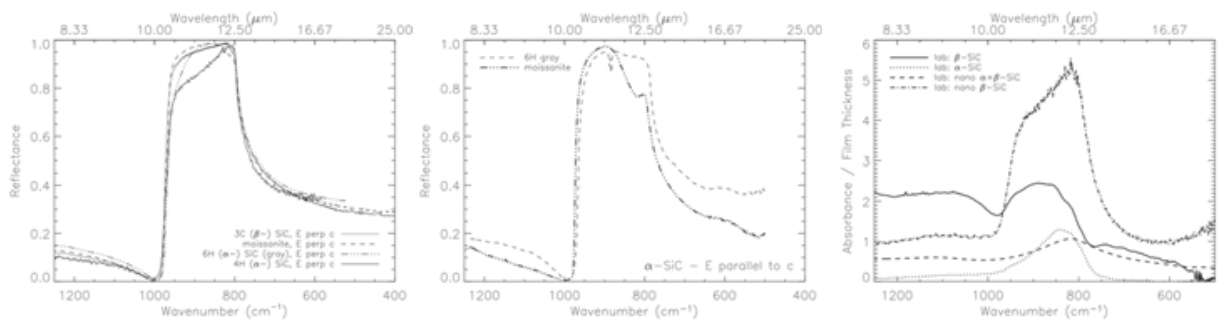

Fig. 7. $\lambda \sim 11 \mu \mathrm{m}$ feature in SiC. Panels $(\mathrm{a}, \mathrm{b})$ : Mid- and mid+far-IR specular reflectivity spectra of bulk $\mathrm{SiC}$, for different orientations. Panel (c): Laboratory (common log) absorbance, divided by thin film thickness for bulk versus nanocrystalline $\beta-\mathrm{SiC}, \alpha-\mathrm{SiC}$, and a mixture of the two. Data from this work, K. M. Pitman et al., A\&A, vol. 483, pp. 661-672, 2008, reproduced with permission (C) ESO.
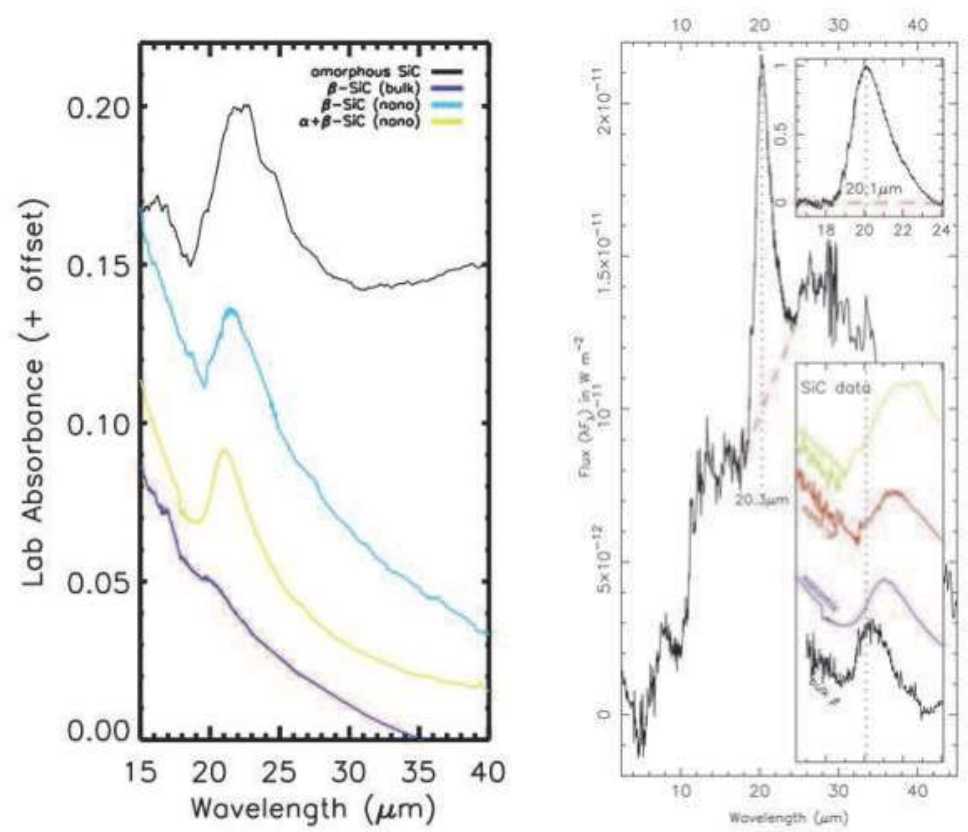

Fig. 8 . The $\lambda \sim 21 \mu \mathrm{m}$ feature in the SiC laboratory spectra is prominent in nanocrystalline and amorphous $\mathrm{SiC}$, present but not as strong in bulk SiC. Laboratory IR absorbance spectra of $\mathrm{SiC}$ shown in bulk, nanocrystalline, amorphous, blends of $\alpha$ - and $\beta$-SiC. Some data from Speck \& Hofmeister (2004); new $\beta$-SiC nanocrystalline data included longward of $20 \mu \mathrm{m}$. At $19.8 \mu \mathrm{m}, \mathrm{a}$ "S-shaped" beamsplitter artifact or spectral spike occurs. The amorphous $\mathrm{SiC}$ sample was polycard (i.e., this spectrum has a different baseline than the other 3 spectra, most noticeable at $\lambda>21 \mu \mathrm{m}$ ). The amorphous $\mathrm{SiC}$ spectrum was offset by 0.19 in vertical axis; the other spectra were not offset. Instrumental noise was smoothed for amorphous $\mathrm{SiC}$ at $\lambda<20 \mu \mathrm{m}$ and again for nanocrystalline $\beta$-SiC spectra at $\lambda>27 \mu \mathrm{m}$. The steep rise to short $\lambda$ occurs because this feature is a shoulder on the main band near $11 \mu \mathrm{m}$. 


\begin{tabular}{|l|c|c|c|}
\hline & Position $\left(\mathrm{cm}^{-1}\right)$ & Height & Width \\
\hline Amorphous $\mathrm{SiC}$ & 450.172 & 0.1340 & 102.16 \\
\hline & & & \\
\hline Nanocrystalline $\beta$-SiC & 463.52 & 0.09291 & 34.3971 \\
\hline & 424.75 & 0.07975 & 58.4357 \\
\hline Nanocrystalline $\alpha+\beta \mathrm{SiC}$ & & & \\
\hline & 472.69 & 0.1274 & 60.794 \\
\hline
\end{tabular}

Table 1. Peak parameters of $\lambda \sim 21 \mu \mathrm{m}$ feature in SiC. Values reported in frequency $\left(\mathrm{cm}^{-1}=\right.$ $\left.10^{4} / \lambda(\mu \mathrm{m})\right)$. Amorphous $\mathrm{SiC}$ spectrum was best fitted with a single Gaussian peak and multi-point baseline correction. Peaks in the IR actually tend to be Lorentzian in shape; the $21 \mu \mathrm{m}$ feature in the nanocrystalline spectra were fitted with two Lorentzian peaks (for the TO and LO modes) and a two-point linear baseline correction.

samples with Si replacing C from 10 to $50 \%$ by various methods; its IR spectrum exhibits bands at 9.5 and $21 \mu \mathrm{m}$, and the relative strength of the $21 \mu \mathrm{m}$ band increases with $\mathrm{C}$ content. On this basis, Kimura et al. (2005a, 2005b) concluded that the $21 \mu \mathrm{m}$ band in IR spectra of SiC samples also results from excess C. Jiang et al. (2005) calculated IR spectra of astronomical dust for various sub- $\mu \mathrm{m}$ grain sizes and a range of peak strengths for the 21 $\mu \mathrm{m}$ band at $\mathrm{T} \sim 70 \mathrm{~K}$. That work concluded that the $21 \mu \mathrm{m}$ feature was too weak to be SiC unless very high concentrations of impurity were observed. However, relative peak intensities are affected by factors not explored in that study. The intensity of emission at 21 $\mu \mathrm{m}$ would be enhanced relative to that at $11 \mu \mathrm{m}$ by either lower temperature or larger (nonuniform) grain sizes. A more serious objection to the assignment is that the astronomy environment could possess Si-rich nano-diamond. Quantifying the strengths of the $21 \mu \mathrm{m}$ $\mathrm{SiC}$ feature in both structures and low temperature measurements is needed to differentiate between these possibilities.

\subsection{Optical functions of SiC}

Optical functions or "optical constants" are the real and imaginary parts of the complex index of refraction $m=n+i k$ that vary as a function of wavelength, temperature, and dust species (composition, structure). $n(\lambda)$ is the real index of refraction where the crystal is not strongly absorbing, and $\mathrm{k}(\lambda)=\mathrm{A} / 4 \pi v$ represents the extinction or gradual loss of intensity due to absorption of photons as an electromagnetic wave interacts with matter. As discussed in the introduction, there is a substantial market for the optical functions of $\mathrm{SiC}$ within the astrophysics community. In the IR, the optical functions of SiC used in 20th century astronomical studies derive primarily from three studies: Bohren \& Huffman (1983), Pégourié (1988), and Laor \& Draine (1993). These data were for $\alpha$-SiC, often in a single polarization, whereas $\mathrm{SiC}$ dust surrounding astronomical objects is $\beta-\mathrm{SiC}$, and included a wavelength shift to "correct" for the $\mathrm{KBr}$ matrix. Pitman et al. (2008) derived and provided electronic tables of $\mathrm{SiC}$ optical functions out to $\lambda \sim 2000 \mu \mathrm{m}$ for $6 \mathrm{H}(\alpha-) \operatorname{SiC}$ in both polarizations as well as 3C ( $\beta$-)SiC; Hofmeister et al. (2009) extended these data shortward into the UV. For all spectral regions, the latter papers showed that $3 \mathrm{C} \mathrm{SiC}$ and the $\mathrm{E} \perp \mathrm{c}$ polarization of $6 \mathrm{H} \mathrm{SiC}$ have almost identical optical functions that can be substituted for each other in modeling astronomical environments. This result agreed with previous work 
by Mutschke et al. (1999). However, optical functions for the $\mathrm{E}||$ c orientation of $6 \mathrm{H} \mathrm{SiC}$ can differ slightly (peaks shifted to lower frequency). Figure 9 presents optical functions for $4 \mathrm{H} \mathrm{SiC}$, with comparison to the other polytypes from Pitman et al. (2008), and optical functions comparing colored versus colorless samples of $\mathrm{SiC}$ from Hofmeister et al. (2009). In the UV, $\mathrm{n}$ and $\mathrm{k}$ were also calculated for $6 \mathrm{H} \mathrm{SiC}$ at $\sim 0.25-1.24 \mu \mathrm{m}$ by Obarich (1971) and Ninomiya \& Adachi (1994); works presented above also included calculated dielectric functions for other polytypes, from which one may further obtain $n$ and $k$ in the UV.


Fig. 9. UV-vis optical functions derived from experimental specular reflectance data via Lorentz-Lorenz classical dispersion analysis, showing the effect of polytype (top panels; $3 \mathrm{C}$ and $6 \mathrm{H}$ from Pitman et al. 2008, $4 \mathrm{H}$ from this work) and of impurities (bottom panels: Hofmeister et al. 2009, applicable to $3 \mathrm{C}$ or $6 \mathrm{H} \mathrm{E} \perp$ c). Left: real index of refraction $\mathrm{n}$. Right: imaginary index of refraction $\mathrm{k}$. With the exception of $6 \mathrm{H} \mathrm{SiC} \mathrm{E} \mathrm{||} \mathrm{c} \mathrm{orientation,} \mathrm{the} \mathrm{optical}$ functions for $\mathrm{SiC}$ are generally similar, regardless of polytype. As compared to $99.8 \%$ pure (colorless) $\mathrm{SiC}$ samples, the effect of impurities in colored $\mathrm{SiC}$ samples manifests in $\mathrm{k}$.

\section{Application \#1: Observational astronomy}

In this section, we outline the ways in which astrophysicists compare laboratory spectra and optical functions of $\mathrm{SiC}$ to determine the nature and evolution of $\mathrm{SiC}$ dust grains around classes of astronomical objects and environments, e.g., C-rich AGB stars (i.e., carbon stars). 


\subsection{Matching spectral features}

The first step in identifying the nature of dust grains in space is to match the positions and widths of astronomically observed spectral features with those seen in laboratory spectra. To do this we must consider what actually contributes to the spectrum when we look at a dusty star. The spectrum, $F_{\lambda}$, is made of contributions to the light from the star (which is essentially a blackbody, or perfect light absorber at all wavelengths) and the circumstellar material. In the infrared, the circumstellar material is dominated by the dust, the emission from which is determined by the species, i.e., composition, crystal structure, size, and shape of the grains. The spectrum can be represented by Eq. 1,

$$
F_{\lambda}=\sum_{i=1, j=1}^{n, m} w_{j} \times Q_{j} \times B_{i}
$$

where $B_{\lambda}(T)$ is the Planck function for a black body of temperature $T$, so that $B_{i}$ represents a single dust grain at a single temperature (of which there are $n$ in total). Each $\mathrm{Q}_{j}$ represents the extinction efficiency (or rate at which a dust particle absorbs, scatters, or extincts light divided by the incident power per unit area) for a single grain type as defined by its size, shape, composition and crystal structure. Each $\mathrm{w}_{\mathrm{j}}$ represents the weighting factor for a single grain type (of which there are $\mathrm{j}$ in total).

For optically thin environments, where there is little or only single-scattering, the spectrum is dominated by starlight, and one can simply subtract a blackbody continuum relevant to the star (which for carbon stars is $\sim 3000 \mathrm{~K}$ ). However, for very dusty environments, starlight is largely absorbed by the dust and re-emitted in the infrared according to the dust grains' optical functions. Often the system is simplified so that the contributions to the spectrum are dominated by a single dust species and Eq. 1 simplifies to Eq. 2,

$$
F_{\lambda}=w \times Q_{\lambda} \times B_{\lambda}(T)
$$

In this case one can fit a (blackbody) continuum to the observed spectrum and divide to derive emissivities of the observed spectral features (e.g., Speck et al. 1997).

The circumstellar shells of carbon stars are expected to be dominated by amorphous or graphitic carbon grains (see Speck et al. 2009 and references therein). These dust species do not have diagnostic infrared features, and contribute to the dust continuum emission alone. However, $\mathrm{SiC}$ does exhibit a strong infrared feature around $11 \mu \mathrm{m}$ as discussed in Section I. The observed $\sim 11 \mu \mathrm{m} \mathrm{SiC}$ feature has been used extensively to investigate the nature and evolution of dust around carbon stars (Little-Marenin, 1986; Baron et al., 1987; Willems, 1988; Chan \& Kwok, 1990; Goebel et al., 1995; Speck et al., 1997; Sloan et al., 1998; Speck et al., 2005; Thompson et al., 2006; Speck et al., 2009), using datasets from both space-based instruments such as the Infrared Astronomical Satellite (IRAS) Low Resolution Spectrometer (LRS: Neugebauer et al., 1984), and the Infrared Space Observatory (ISO: Kessler et al., 1996) Short Wavelength Spectrometer (SWS: de Graauw et al., 1996), as well as instruments in ground-based observatories (e.g., CGS3 on the United Kingdom Infrared Telescope, UKIRT). In fact, the parameters most commonly used to make identifications of $\mathrm{SiC}$ dust in space are the strength and peak position of the $\sim 11 \mu \mathrm{m}$ feature. From ISO data, there is also a range in shapes and peak positions of the $\sim 11 \mu \mathrm{m} \mathrm{SiC}$ feature that cannot be simply correlated with the apparent temperature of the 
underlying continuum (Thompson et al., 2006). However, there remain several common trends that exist in the observed $\mathrm{SiC}$ features:
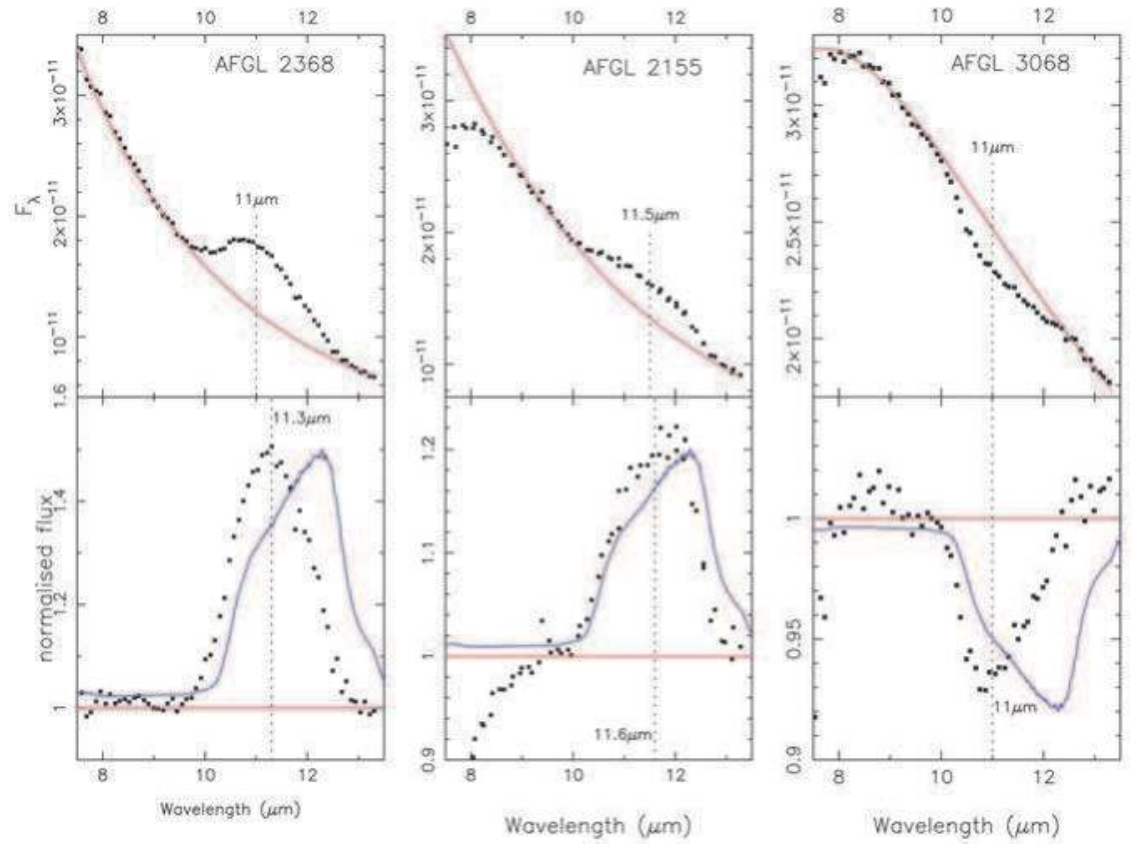

Fig. 10. The $11 \mu \mathrm{m} \mathrm{SiC} \mathrm{feature,} \mathrm{observed} \mathrm{in} \mathrm{the} \mathrm{spectra} \mathrm{of} \mathrm{carbon} \mathrm{stars.} \mathrm{Left} \mathrm{hand} \mathrm{panels}$ represent stars that have the optically thinnest dust shells; optical depth increases to the right. Top panels: Ground-based observed spectra (black symbols: Speck et al. 1997) with best-fitting blackbody continua (red lines). Bottom panels: Continuum-divided spectra, following Eq. 2, provide the effective $Q$-values or extinction efficiencies for the dust shells. Blue lines: $\beta$-SiC absorbance data of Pitman et al. (2008), converted to absorptivity $\mathrm{A}=$ $\mathrm{e}^{\text {absorbance, }}$ is proportional to $\mathrm{Q}$.

i. Early in the AGB phase, when the mass-loss rate is low and the shell is optically thin, the $\sim 11 \mu \mathrm{m} \mathrm{SiC} \mathrm{emission} \mathrm{feature} \mathrm{is} \mathrm{strong,} \mathrm{narrow,} \mathrm{and} \mathrm{sharp.}$

ii. As the mass loss increases and the shell becomes optically thicker, the SiC emission feature broadens, flattens, and weakens.

iii. Once the mass-loss rate is extremely high and the shell is optically thick, the SiC feature appears in absorption.

iv. Once the AGB phase ends and the thinning dust shell cools, $\mathrm{SiC}$ is more rarely observed but may be hidden by other emerging spectral features.

\section{Application \#2: Radiative transfer modeling}

Radiative transfer (RT) modeling uses the optical functions of candidate minerals to model how a given object should look both spectroscopically and in images. Mineral candidates determined by spectral matching can then be input into numerical RT models; examples of 
codes used to solve the equation of radiative transfer are DUSTY (Nenkova et al. 2000) and 2-Dust (Ueta \& Meixner 2003). The acquisition of new optical functions, for SiC and all materials posited to exist in space, is critical to these numerical efforts. Astrophysicists use RT modeling to determine the effects of grain size and shape distributions, chemical composition and mineralogies, temperature and density distributions on the expected astronomical spectrum, and to place constraints on the relative abundances of different grain types in a dust shell. In this way, astrophysicists can build a list of parameters that describes the circumstellar environment around a star.

In radiative transfer modeling, one simulates $\mathrm{SiC}$ dust in space by specifying best estimates for the optical functions, sizes, and shape distributions of the particles. The optical functions mentioned in Section 3 have been tested in a variety of radiative transfer applications. The optical functions of Bohren \& Huffman (1983), Pégourié (1988), and Laor \& Draine (1993) were used to place limits on the abundance of SiC dust in carbon stars (e.g., Martin \& Rogers 1987; Lorenz-Martins \& Lefevre 1993, 1994; Lorenz-Martins et al. 2001; Groenewegen 1995; Groenewegen et al. 1998, 2009; Griffin 1990, 1993; Bagnulo et al. 1995, 1997, 1998), Large Magellanic Cloud stars (Speck et al. 2006; Srinivasan et al. 2010), and (proto-)planetary nebulae (Clube \& Gledhill 2004; Hoare 1990; Jiang et al. 2005). Those optical functions have also been used in studies of dust formation (e.g., Kozasa et al. 1996), hydrodynamics of circumstellar shells (e.g., Windsteig et al. 1997; Steffen et al. 1997), and mean opacities (Ferguson et al. 2005; Alexander \& Ferguson 1994). In their radiative transfer models of dust around C-stars, Groenewegen et al. (2009) offered a comparison of the performance of the optical functions of Pitman et al. (2008), shown in Figure 3.5, against a-SiC from Pégourié (1988), and $\beta$-SiC from Borghesi et al. (1985) in matching observed $11 \mu \mathrm{m}$ features in astronomical spectra. Ladjal et al. (2010) concluded that the Pitman et al. (2008) modeled the shape and peak position of the $11 \mu \mathrm{m}$ feature well in evolved stars. The intrinsic shape for SiC grains in circumstellar environments is not known but distributions of complex, nonspherical shapes (Continuous Distribution of Ellipsoids, CDE, Bohren \& Huffman 1983; Distribution of Hollow Spheres, Min et al. 2003; aggregates, Andersen et al. 2006, and references therein) are the best estimate at present. Most of these produce a feature at $\lambda \sim 11 \mu \mathrm{m}$ that is broad as compared to laboratory $\mathrm{SiC}$ spectra, but matches astronomically observed spectra. There is no clear consensus on what the grain size distribution for $\mathrm{SiC}$ grains in space should be (see review by Speck et al. 2009). SiC dust is generally found in circumstellar, not interstellar, dust, which limits the assumptions on size. Strictly speaking, the SiC optical functions of Pégourié (1988) and Laor \& Draine (1993) should be used with the corresponding grain size distribution of the ground and sedimented $\mathrm{SiC}$ sample measured in the lab ( $\propto$ diameter-2.1, with an average grain diameter $=0.04 \mu \mathrm{m}$ ). Bulk $\mathrm{n}$ and $\mathrm{k}$ datasets (e.g., Pitman et al. 2008; Hofmeister et al. 2009) can be used with any grain size distribution.

Once optical functions, sizes, and shape distributions have been selected for the $\mathrm{SiC}$ particles, astrophysicists are free to test the influence of percent $\mathrm{SiC}$ dust content on an astronomical spectrum. Figure 11 gives examples of synthetic spectra of SiC-bearing dust shells of varying optical thicknesses around a $\mathrm{T}=3000 \mathrm{~K}$ star using the radiative transfer code DUSTY. Simply changing the optical functions and/or shape distribution results in substantial differences in the modeled astronomical spectrum, and thus interpretations of the self-absorption and emission in the circumstellar dust shell. 

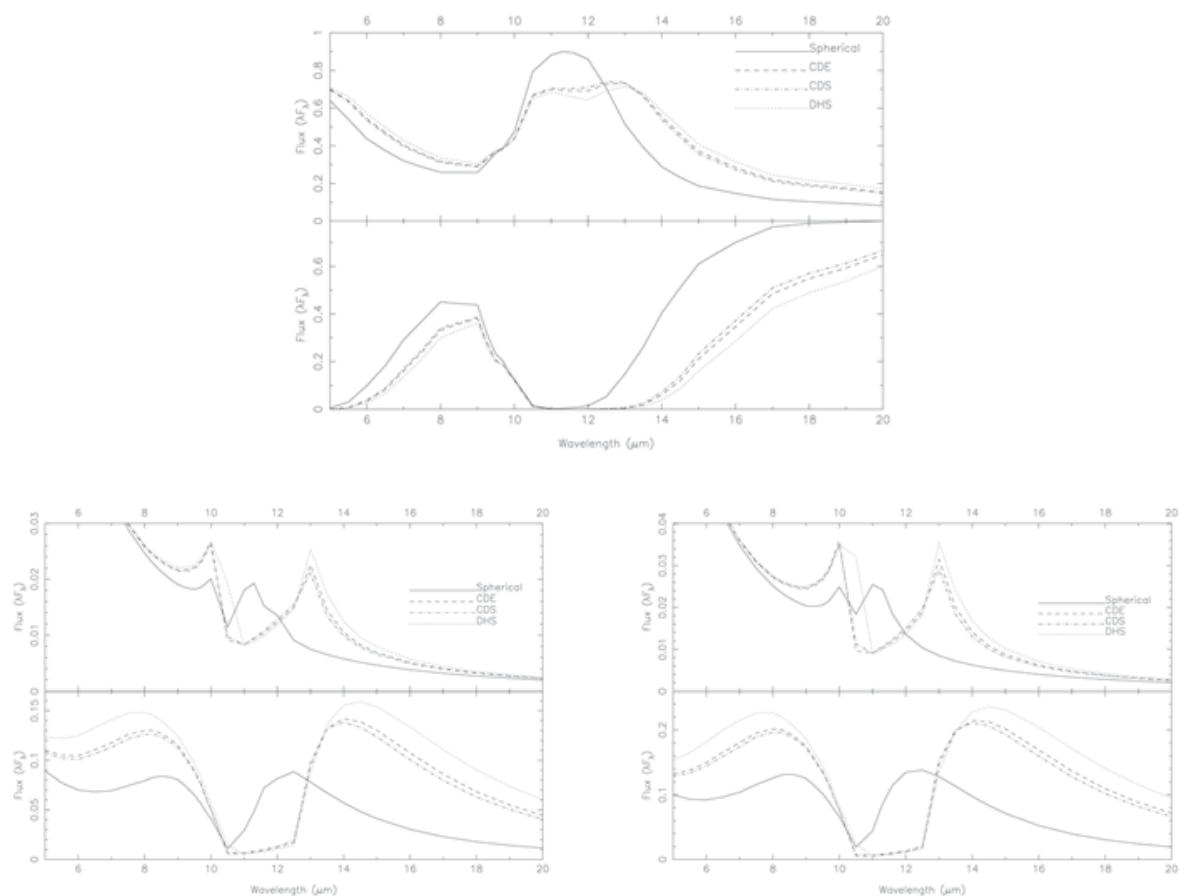

Fig. 12. Synthetic spectra of stellar light flux generated with DUSTY code. Top panel: Pégourié (1988) $\alpha$-SiC optical functions. Bottom panel: Pitman et al. (2008) SiC optical functions. Left hand versus right hand columns compare $\alpha$-SiC (weighted average of $1 / 3$ $\mathrm{E}|| \mathrm{c}, 2 / 3 \mathrm{E} \perp \mathrm{c}$ ) versus $\beta$-SiC. Line styles compare different shape distributions (spherical, $\mathrm{CDE}, \mathrm{CDS}=$ continuous distribution of ellipsoids; spheroids, DHS = distribution of hollow spheres). See Corman (2010) and Corman et al. (2011) for more examples.

\section{Conclusion}

Since the 1960s, laboratory and theoretical astrophysics investigations of $\mathrm{SiC}$ grains have culminated in several important findings:

1. $~ 99 \%$ of meteoritic $\mathrm{SiC}$ grains were formed around carbon-rich Asymptotic Giant Branch stars, and that of these, $>95 \%$ originate around low-mass $\left(<3 \mathrm{M}_{\odot}\right)$ carbon stars;

2. Nearly all $\mathrm{SiC}$ grains in space are crystalline, with $>80 \%$ of these occurring as the cubic $3 \mathrm{C}$ polytype, and the rest comprising the lower temperature $2 \mathrm{H}$ polytype or $3 \mathrm{C} / 2 \mathrm{H}$ combinations;

3. The grain size distribution of $\mathrm{SiC}$ in space includes both very small and very large grains $(1.5 \mathrm{~nm}-26 \mu \mathrm{m})$, with most grains in the $0.1-1 \mu \mathrm{m}$ range. Single-crystal $\mathrm{SiC}$ grains can exceed $20 \mu \mathrm{m}$ in size. The sizes of individual SiC crystals are correlated with s-process element concentration.

4. There is no consensus on the shape of $\mathrm{SiC}$ particles in space. SEM and TEM imagery of presolar $\mathrm{SiC}$ grains provides a guide. In numerical radiative transfer model calculations, 
distributions of complex, nonspherical shapes (continuous distributions of ellipsoids or hollow spheres; fractal aggregates) are assumed.

5. Complimentary spectroscopic measurements of synthetic $\mathrm{SiC}$ made by the semiconductor and astrophysics communities have provided consistent values for optical functions, once different methodologies have been accounted for. Laboratory astrophysics studies of $\mathrm{SiC}$ focus on general UV spectral behavior and two specific IR spectral features (at $\lambda \sim 11 \mu \mathrm{m}, 21 \mu \mathrm{m}$ ) that can be matched to astronomical spectra. The effects of orientation, polytype, and impurities in $\mathrm{SiC}$ are all important to astronomical studies.

6. Variations in optical functions with impurities and structure, as well as assumptions on size and shape distributions, strongly affects the amount of light scattering and absorption inferred in space.

Optical properties of SiC warrant future study. Vacuum UV data from the semiconductor literature need to be better integrated into the astrophysics literature. Laboratory studies on $\mathrm{SiC}$ have considered the effect of varying temperature from early on (e.g., Choyke \& Patrick 1957). However, most data were collected only at room temperature. Temperaturedependent spectra and optical functions are necessary, especially low-temperature measurements. Chemical vapor-deposited $\mathrm{SiC}$ samples are available from the semiconductor industry for $\beta$-SiC. For future work, other forms of $\beta$-SiC would be better for determining optical functions, e.g., single crystals for the non-absorbing near-IR to visible region. Further measurements of solid solutions of $\mathrm{SiC}$ and $\mathrm{C}$, with focus on impurities likely to be incorporated in astrophysical environments rather than doped crystals, should be pursued in the UV. Although IR spectra of $2 \mathrm{H} \mathrm{SiC}$ can be constructed from available data (e.g., Lambrecht et al. 1997) because folded modes are not present, $2 \mathrm{H} \mathrm{SiC}$ also warrants direct measurement for its importance in space.

\section{Acknowledgment}

Authors' laboratory and theoretical work shown in this chapter was kindly supported by the National Science Foundation under grants NSF-AST-1009544, NASA APRA04-000-0041, NSF-AST-0607341, and NSF-AST-0607418. Credit: K. M. Pitman et al., A\&A, vol. 483, pp. 661-672, 2008, reproduced with permission () ESO. Data from Speck \& Hofmeister (2004) and Hofmeister et al. (2009) reproduced with permission from the AAS. Figure 2.2 was kindly provided by T. Bernatowicz. The authors thank Jonas Goldsand for his assistance on laboratory sample preparation and data collection. This is PSI Contribution No. 506.

\section{References}

Adolph, B., Tenelsen, K., Gavrilenko, V. I., \& Bechstedt, F. (1997). Optical and loss spectra of $\mathrm{SiC}$ polytypes from ab initio calculations, Phys. Rev. B, Vol. 55, pp. 1422-1429

Alexander, D. R., \& Ferguson, J. W. (1994). Low-temperature Rosseland opacities, Astrophys. J., Vol. 437, No. 2, pp. 879-891

Amari, S., Lewis, R. S., \& Anders, E. (1994). Interstellar grains in meteorites. I - Isolation of $\mathrm{SiC}$, graphite, and diamond, size distributions of $\mathrm{SiC}$ and graphite. II - SiC and its noble gases, Geochim. Cosmochim. Ac., Vol. 58, p. 459.

Amari, S., Hoppe, P., Zinner, E., \& Lewis, R. S. (1992). Interstellar SiC with unusual isotopic compositions - Grains from a supernova?, Astrophys. J. Lett., Vol. 394, pp. L43-L46. 
Amari, S., Hoppe, P., Zinner, E., \& Lewis, R. S. (1995). Trace-element concentrations in single circumstellar silicon carbide grains from the Murchison meteorite, Meteoritics, Vol. 30, No. 6, p. 679

Amari, S., Zinner, E., \& Lewis, R. S. (1996) CA and TI Isotopic Compositions of SizeSeparated SiC Fractions from the Murchison Meteorite, Lunar Planet. Sci., Vol. 27, page 23

Amari, S., Nittler, L. R., Zinner, E., \& Lewis, R. S. (1997a). Presolar SiC Grains of Type A+B, Meteorit. Planet. Sci., Vol. 32, p. A6

Amari, S., Nittler, L. R., Zinner, E., \& Lewis, R. S. (1997b). Continued search for rare types of presolar SiC - Grains X and Y, Lunar Planet. Sci., Vol. 28, p. 33.

Anders, E., \& Zinner, E. (1993). Invited Review - Interstellar grains in primitive meteorites: Diamond, silicon carbide, and graphite, Meteoritics, Vol. 28, pp. 490-514

Andersen, A. C., Loidl, R., \& Höfner, S. (1999). Optical properties of carbon grains: Influence on dynamical models of AGB stars, Astron. Astrophys., Vol. 349, pp. 243252

Andersen, A. C., Mutschke, H., Posch, Th., Min, M., \& Tamanai, A. (2006). Infrared extinction by homogeneous particle aggregates of $\mathrm{SiC}, \mathrm{FeO}$ and $\mathrm{SiO}_{2}$ : Comparison of different theoretical approaches, J. Quant. Spectrosc. Rad. Trans., Vol. 100, No. 13, pp. $4-15$

Bagnulo, S., Doyle, J. G., \& Griffin, I. P. (1995). A study of the size and composition of dust grains in the circumsteller envelope of IRC +10 216, Astron. Astrophys., Vol. 301, p. 501

Bagnulo, S., Doyle, J. G., \& Andretta, V. (1998). Observations and modelling of spectral energy distributions of carbon stars with optically thin envelopes, Mon. Not. R. Astron. Soc., Vol. 296, pp. 545-563

Bagnulo, S., Skinner, C. J., Doyle, J. G., \& Camphens, M. (1997). Carbon stars with detached dust shells: the circumstellar envelope of UU Aurigae, Astron. Astrophys., Vol. 321, pp. 605-617

Baron, Y., Papoular, R., Jourdain de Muizon, M., \& Pégourié, B. (1987). An analysis of the emission features of the IRAS low-resolution spectra of carbon stars, Astron. Astrophys., Vol. 186, p. 271

Barzyk, J. G. (2007). Multielement isotopic analysis of presolar silicon carbide, Ph.D. thesis (Proquest, AAT 3252254), The University of Chicago, Illinois, USA, 102 pages

Belle, M. L., Prokofeva, N. K., \& Reifman, M. B. (1967). Soviet Phys. - Semicond., Vol. 1, p. 315

Bernatowicz, T. J., Croat, T. K., \& Daulton, T. L. (2006). Origin and Evolution of Carbonaceous Presolar Grains in Stellar Environments, In: Meteorites and the Early Solar System II, eds. D. S. Lauretta \& H. Y. McSween, Jr. (Tucson: University of Arizona Press), 109

Bernatowicz, T., Fraundorf, G., Ming, T., Anders, E., Wopenka, B., Zinner, E., \& Fraundorf, P. (1987). Evidence for interstellar $\mathrm{SiC}$ in the Murray carbonaceous meteorite, Nature, Vol. 330, No. 24, p. 728-730

Bernatowicz, T., Fraundorf, G., Fraundorf, P., \& Tang, M. (1988a). TEM Observations of Interstellar Silicon Carbide from the Murray and Murchison Carbonaceous Meteorites, 51st Meeting of the Meteoritical Society, July 18-22, 1988, Fayetteville, Arkansas, No. 665, p.1 
Bernatowicz, T., Fraundorf, G., Fraundorf, P., \& Ming, T. (1988b). TEM Observations of Interstellar Silicon Carbide from the Murray and Murchison Carbonaceous Meteorites, Meteoritics, Vol. 23, p. 257

Bernatowicz, T. J., Akande, O. W., Croat, T. K., \& Cowsik, R. (2005). Constraints on Grain Formation around Carbon Stars from Laboratory Studies of Presolar Graphite, Astrophys. J., Vol. 631, p. 988

Besmehn, A., \& Hoppe, P. (2002). NanoSIMS Study of an Unusual Silicon Carbide X Grain from the Murchison Meteorite, Meteorit. Planet. Sci., Vol. 37, Supplement, p. A17

Blöcker, T., \& Schönberner, D. (1991). New pre-white dwarf evolutionary tracks, In: White Dwarfs, NATO Advanced Science Institutes (ASI) Series C, Vol. 336, eds. G. Vauclair, E. Sion, p. 1, Kluwer, Dordrecht

Bohren, C. F., \& Huffman, D. R. (1983). Absorption and Scattering of Light by Small Particles, John Wiley \& Sons Inc., ISBN 0-471-29340-7, New York, 530 pp.

Borghesi, A., Bussoletti, E., Colangeli, L., \& de Blasi, C. 1985, Laboratory study of SiC submicron particles at IR wavelengths - A comparative analysis, Astron. Astrophys., Vol. 153, No. 1, pp. 1-8

B2FH = Burbidge, E. M., Burbidge, G. R., Fowler, W. A., \& Hoyle, F. (1957). Synthesis of the Elements in Stars, Rev. Mod. Phys., Vol. 29, p. 547

Cameron, A. G. W. (1957). Nuclear Reactions in Stars and Nucleogenesis, Publ. Astron. Soc. Pac., Vol. 69, p. 201

Chan, S. J., \& Kwok, S. (1990). Evolution of infrared carbon stars, Astron. Astrophys., Vol. 237, p. 354

Choyke, W. J., \& Patrick, L. (1957). Absorption of Light in Alpha SiC near the Band Edge, Phys. Rev., Vol. 105, p. 1721

Choyke, W. J., \& Patrick, L. (1968). Higher Absorption Edges in 6H SiC, Phys. Rev., Vol. 172, No. 3, pp. 769-772

Choyke, W. J., \& Patrick, L. (1969). Higher Absorption Edges in Cubic SiC, Phys. Rev., Vol. 187, No. 3, pp. 1041-1043

Clayton, D. D., \& Nittler, L. R. (2004). Astrophysics with Presolar Stardust, Annu. Rev. Astron. Astr., Vol. 42, p. 39

Clément, D., Mutschke, H., Klein, R., \& Henning, Th. (2003). New Laboratory Spectra of Isolated $\beta$-SiC Nanoparticles: Comparison with Spectra Taken by the Infrared Space Observatory, Astrophys. J., Vol. 594, No. 1, pp. 642-650

Clube, K. L., \& Gledhill, T. M. (2004). Mid-infrared imaging and modelling of the dust shell around post-AGB star HD 187885 (IRAS 19500-1709), Mon. Not. R. Astron. Soc., Vol. 355, No. 3, pp. L17-L21

Corman, A. B. (2010). Carbon Stars and Silicon Carbide, PhD thesis, University of MissouriColumbia, USA

Corman, A. B., Hofmeister, A. M., Speck, A. K., \& Pitman, K. M. (2011). Optical Constants of Silicon Carbide. III. Shape Effects on Small Silicon Carbide Grains, Astrophys. J., in preparation

Daulton, T. L., Bernatowicz, T. J., Lewis, R. S., Messenger, S., Stadermann, F. J., \& Amari, S. (2002). Polytype Distribution in Circumstellar Silicon Carbide, Science, Vol. 296, No. 5574, pp. 1852-1855

Daulton, T. L., Bernatowicz, T. J., Lewis, R. S., Messenger, S., Stadermann, F. J., \& Amari, S. (2003). Polytype distribution of circumstellar silicon carbide - microstructural 
characterization by transmission electron microscopy, Geochim. Cosmochim. Ac., Vol. 67, No. 24, pp. 4743-4767

de Graauw, T., et al. (1996). Observing with the ISO Short-Wavelength Spectrometer, Astron. Astrophys., Vol. 315, pp. L49-L54

Devaty, R. P., \& Choyke, W. J. (1997). Optical Characterization of Silicon Carbide Polytypes, Phys. Status Solidi (A), Applied Research, Vol. 162, No. 1, pp. 5-38

Ferguson, J. W., Alexander, D. R., Allard, F., Barman, T., Bodnarik, J. G., Hauschildt, P. H., Heffner-Wong, A., \& Tamanai, A. (2005). Low-Temperature Opacities, Astrophys. J., Vol. 623, No. 1, pp. 585-596

Friedemann, C. (1969). Evolution of silicon carbide particles in the atmospheres of carbon stars, Physica, Vol. 41, p. 139

Friedemann, C., Gürtler, J., Schmidt, R., \& Dorschner, J. (1981). The 11.5 micrometer emission from carbon stars - Comparison with IR spectra of submicrometer-sized silicon carbide grains, Astrophys. Space Sci., Vol. 79, No. 2, pp. 405-417

Gavrilenko, V. I. (1995). Calculated differential reflectance of the (110) surface of cubic silicon carbide, Appl. Phys. Lett., Vol. 67, pp. 16-18

Gavrilenko, V. I., \& Bechstedt, F. (1997). Optical functions of semiconductors beyond density-functional theory and random-phase approximation, Phys. Rev. B, Vol. 55, No. 7, pp. 4343-4352

Gilman, R. C. (1969). On the Composition of Circumstellar Grains, Astrophys. J., Vol. 155, p. L185

Gilra, D. P. (1971). Composition of Interstellar Grains, Nature, Vol. 229, No. 5282, pp. 237-241

Gilra, D.P. (1972). Collective Excitations in Small Solid Particles and Astronomical Applications, Ph.D. thesis, University of Wisconsin-Madison, Dissertation Abstracts International, Vol. 33-11, Sect. B, p. 5114

Goebel, J. H., Cheeseman, P., \& Gerbault, F. (1995). The 11 Micron Emissions of Carbon Stars, Astrophys. J., Vol. 449, p. 246

Griffin, I. P. (1990). A model for the infrared and radio spectral energy distribution of IRC + 10 deg 216, Mon. Not. R. Astron. Soc., Vol. 247, pp. 591-605

Griffin, I. P. (1993). A model for the circumstellar envelope of WX SER, Mon. Not. R. Astron. Soc., Vol. 260, pp. 831-843

Groenewegen, M. A. T. (1995). Dust shells around infrared carbon stars, Astron. Astrophys., Vol. 293, pp. 463-478.

Groenewegen, M. A. T., Whitelock, P. A., Smith, C. H., \& Kerschbaum, F. (1998). Dust shells around carbon Mira variables, Mon. Not. R. Astron. Soc., Vol. 293, p. 18

Groenewegen, M. A. T., Sloan, G. C., Soszyński, I., \& Petersen, E. A. (2009). Luminosities and mass-loss rates of SMC and LMC AGB stars and red supergiants, Astron. Astrophys., Vol. 506, No. 3, pp. 1277-1296

Gyngard, F. (2009). Isotopic studies of presolar silicon carbide and oxide grains as probes of nucleosynthesis and the chemical evolution of the galaxy, Ph.D. thesis (Proquest, AAT 3387342), Washington University in St. Louis, USA, 165 pp.

Hackwell, J. A. (1972). Long wavelength spectrometry and photometry of M, S and C-stars, Astron. Astrophys., Vol. 21, p. 239

Heck, P. R. (2005) Helium and neon in presolar silicon carbide grains and in relict chromite grains from fossil meteorites and micrometeorites as tracers of their origin, Ph.D. 
thesis Proquest, AAT C821918), Eidgenoessische Technische Hochschule Zuerich (Switzerland), $155 \mathrm{pp}$.

Heck, P. R., Pellin, M. J., Davis, A. M., Martin, I., Renaud, L., Benbalagh, R., Isheim, D., Seidman, D. N., Hiller, J., Stephan, T., Lewis, R. S., Savina, M. R., Mane, A., Elam, J., Stadermann, F. J., Zhao, X., Daulton, T. L., \& Amari, S. (2010). Atom-Probe Tomographic Analyses of Presolar Silicon Carbide Grains and Meteoritic Nanodiamonds - First Results on Silicon Carbide, 41st Lunar Planet. Sci. Conf., March 1-5, 2010, The Woodlands, Texas, No. 1533, p. 2112

Henkel, T., Stephan, T., Jessberger, E. K., Hoppe, P., Strebel, R., Amari, S., \& Lewis, R. S. (2007). 3-D elemental and isotopic composition of presolar silicon carbides, Meteorit. Planet. Sci., Vol. 42, No. 7, pp. 1121-1134

Henning, T. (2010). Laboratory Astrophysics of Cosmic Dust Analogues, In: Lecture Notes in Physics 815 Astromineralogy (2nd ed.), Th. Henning (ed.), pp. 313-329, SpringerVerlag, ISBN 978-3-642-13258-2, Berlin, Heidelberg

Hoare, M. G. (1990). The dust content of two carbon-rich planetary nebulae, Mon. Not. R. Astron. Soc., Vol. 244, pp. 193-206

Hofmeister, A. M., Keppel, E., \& Speck, A. K. (2003). Absorption and reflection infrared spectra of $\mathrm{MgO}$ and other diatomic compounds, Mon. Not. R. Astron. Soc., Vol. 345, No. 1, pp. 16-38

Hofmeister, A. M., Pitman, K. M., Goncharov, A. F., \& Speck, A. K. (2009) Optical Constants of Silicon Carbide for Astrophysical Applications. II. Extending Optical Functions from Infrared to Ultraviolet Using Single-Crystal Absorption Spectra, Astrophys. J., Vol. 696, No. 2, pp. 1502-1516

Hoppe, P. (2009). Stardust in Meteorites and IDPs: Current Status, Recent Advances, and Future Prospects, In: Cosmic Dust - Near and Far, ASP Conference Series, Vol. 414, ed. Th. Henning, E. Grün, \& J. Steinacker, p.148

Hoppe, P., \& Besmehn, A. (2002). Evidence for Extinct Vanadium-49 in Presolar Silicon Carbide Grains from Supernovae, Astrophys. J., Vol. 576, No. 1, pp. L69-L72.

Hoppe, P., \& Ott, U. (1997). Mainstream silicon carbide grains from meteorites, In: Astrophysical implications of the laboratory study of presolar materials, AIP Conference Proceedings, Vol. 402, pp. 27-58

Hoppe, P., \& Zinner, E. (2000). Presolar dust grains from meteorites and their stellar sources, J. Geophys. Res., Vol. 105, No. A5, pp. 10371-10386

Hoppe, P., Amari, S., Zinner, E., Ireland, T., \& Lewis, R. S. (1994a). Carbon, nitrogen, magnesium, silicon, and titanium isotopic compositions of single interstellar silicon carbide grains from the Murchison carbonaceous chondrite, Astrophys. J., Vol. 430, No. 2, pp. $870-890$

Hoppe, P., Pungitore, B., Eberhardt, P., Amari, S., \& Lewis, R. S. (1994b) Ion imaging of small interstellar grains, Meteoritics, Vol. 29, No. 4, pp. 474-475

Hoppe, P., Strebel, R., Eberhardt, P., Amari, S., \& Lewis, R. S. (1996) Small SiC grains and a nitride grain of circumstellar origin from the Murchison meteorite: Implications for stellar evolution and nucleosynthesis, Geochim. Cosmochim. Ac., Vol. 60, No. 5, pp. 883-907

Hoppe, P., Strebel, R., Eberhardt, P., Amari, S., \& Lewis, R. S. (2000) Isotopic properties of silicon carbide $X$ grains from the Murchison meteorite in the size range 0.5-1.5 $\mu \mathrm{m}$, Meteorit. Planet. Sci., Vol. 35, No. 6, pp. 1157-1176 
Hoppe, P., Lodders, K., Strebel, R., Amari, S., \& Lewis, R. S. (2001). Boron in Presolar Silicon Carbide Grains from Supernovae, Astrophys. J., Vol. 551, No. 1, pp. 478-485

Huffman, D. R. (1988). Methods and Difficulties in Laboratory Studies of Cosmic Dust Analogues, In: Experiments on Cosmic Dust Analogues, eds. E. Bussoletti, C. Fusco, \& G. Longo, Astrophysics and Space Science Library, Vol. 149, p. 25, Kluwer Academic Publishers, Dordrecht.

Iben, I., Jr., \& Renzini, A. (1983). Asymptotic giant branch evolution and beyond, in: Annual review of Astron. Astrophys.. Vol. 21 (Palo Alto, CA, Annual Reviews, Inc.), pp. 271-342

Ismail, A. M., \& Abu-Safia, H. (2002). Calculated and measured reflectivity of some p-type SiC polytypes, J. Appl. Phys., Vol. 91, No. 7, pp. 4114-4116

Jennings, C. L., Savina, M. R., Messenger, S., Amari, S., Nichols, R. H., Jr., Pellin, M. J., \& Podosek, F. A., (2002). Indarch SiC by TIMS, RIMS, and NanoSIMS, 33rd Lunar Planet. Sci. Conf., March 11-15, 2002, Houston, Texas, abstract no. 1833

Jiang, B. W., Zhang, K., \& Li, A. (2005). On Silicon Carbide Grains as the Carrier of the 21 $\mu \mathrm{m}$ Emission Feature in Post-Asymptotic Giant Branch Stars, Astrophys. J., Vol. 630, No. 1, pp. L77-L80

Kessler, M. F., Steinz, J. A.; Anderegg, M. E.; Clavel, J.; Drechsel, G.; Estaria, P.; Faelker, J.; Riedinger, J. R.; Robson, A.; Taylor, B. G.; Ximénez de Ferrán, S. (1996). The Infrared Space Observatory (ISO) mission, Astron. Astrophys., Vol. 315, No. 2, pp. L27 - L31

Kimura, Y., Nuth, J. A., III, \& Ferguson, F. T. (2005a). Is the 21 Micron Feature Observed in Some Post-AGB Stars Caused by the Interaction between Ti Atoms and Fullerenes? Astrophys. J., Vol. 632, No. 2, pp. L159-L162

Kimura, Y., Ishikawa, M., Kurumada, M., Tanigaki, T., Suzuki, H., \& Kaito, C. (2005b). Crystal structure and growth of carbon-silicon mixture film prepared by ion sputtering, Journal of Crystal Growth, Vol. 275, pp. e977-e981

Kozasa, T., Dorschner, J., Henning, Th., \& Stognienko, R. (1996). Formation of SiC grains and the $11.3 \mu \mathrm{m}$ feature in circumstellar envelopes of carbon stars, Astron. Astrophys., Vol. 307, pp. 551-560

Kwok, S., Volk, K. M., \& Hrivnak, B. J. (1989). A 21 micron emission feature in four protoplanetary nebulae, Astrophys. J. Lett., Vol. 345, pp. L51-L54

Ladjal, D., Justtanont, K., Groenewegen, M. A. T., Blommaert, J. A. D. L., Waelkens, C., \& Barlow, M. J. (2010). $870 \mu \mathrm{m}$ observations of evolved stars with LABOCA, Astron. Astrophys., Vol. 513, p. A53

Lambrecht, W. R. L., Segall, B., Suttrop, W., Yoganathan, M., Devaty, R. P., Choyke, W. J., Edmond, J. A., Powell, J. A., \& Alouani, M. (1993). Optical reflectivity of 3C and 4H-SiC polytypes: Theory and experiment, Appl. Phys. Lett., Vol. 63, pp. 2747- 2749

Lambrecht, W. R. L., Segall, B., Yoganathan, M., Suttrop, W., Devaty, R. P., Choyke, W. J., Edmond, J. A., Powell, J. A., \& Alouani, M. (1994). Calculated and measured uv reflectivity of SiC polytypes, Phys. Rev. B, Vol. 50, pp. 10722-10726

Lambrecht, W. R. L., Limpijumnong, S., Rashkeev, S. N., \& Segall, B. (1997). Electronic Band Structure of SiC Polytypes: A Discussion of Theory and Experiment, Phys. Status Solidi (B), Applied Research, Vol. 202, No. 1, pp. 5-33

Laor, A., \& Draine, B. T. (1993). Spectroscopic constraints on the properties of dust in active galactic nuclei, Astrophys. J., Vol. 402, No. 2, pp. 441-468 
Lindquist, O. P. A., Schubert, M., Arwin, H., \& Jarrendahl, K. (2004). Infrared to vacuum ultraviolet optical properties of $3 \mathrm{C}, 4 \mathrm{H}$ and $6 \mathrm{H}$ silicon carbide measured by spectroscopic ellipsometry, Thin Solid Films, Vol. 455-456, pp. 235-238

Little-Marenin, I. R. (1986). Carbon stars with silicate dust in their circumstellar shells, Astrophys. J. Lett., Vol. 307, pp. L15-L19

Logothetidis, S., \& Petalas, J. (1996). Dielectric function and reflectivity of 3C-silicon carbide and the component perpendicular to the $\mathrm{c}$ axis of $6 \mathrm{H}$-silicon carbide in the energy region 1.5-9.5 eV, J. Appl. Phys., Vol. 80, pp. 1768- 1772

Lorenz-Martins, S., \& Lefevre, J. (1993). SiC in circumstellar shells around C stars, Astron. Astrophys., Vol. 280, pp. 567-580

Lorenz-Martins, S., \& Lefevre, J. (1994). SiC grains and evolution of carbon stars, Astron. Astrophys., Vol. 291, pp. 831-841

Lorenz-Martins, S., de Araújo, F. X., Codina Landaberry, S. J., de Almeida, W. G., \& de Nader, R. V. (2001). Modeling of C stars with core/mantle grains: Amorphous carbon $+\mathrm{SiC}$, Astron. Astrophys., Vol. 367, pp. 189-198

Lubinsky, A. R., Ellis, D. E., \& Painter, G. S. (1975). Electronic structure and optical properties of 3C-SiC, Phys. Rev. B, Vol. 11, p. 1537

Martin, P. G., \& Rogers, C. (1987). Carbon grains in the envelope of IRC +10216, Astrophys. J., Vol. 322, pp. 374-392

Mauron, N., \& Huggins, P. J. (2006). Imaging the circumstellar envelopes of AGB stars, Astron. Astrophys., Vol. 452, pp. 257-268

Min, M., Hovenier, J. W., \& de Koter, A. (2003). Shape effects in scattering and absorption by randomly oriented particles small compared to the wavelength, Astron. Astrophys., Vol. 404, pp. 35-46

Mutschke, H., Andersen, A. C., Clément, D., Henning, Th., \& Peiter, G. (1999). Infrared properties of SiC particles, Astron. Astrophys., Vol. 345, pp. 187-202

Nakashima, S., \& Harima, H. (1997). Raman Investigation of SiC Polytypes, Physica Status Solidi A - Applied Research, Vol. 162, p. 39

Nenkova, M., Ivezic, Z., \& Elitzur, M. (2000). Thermal Emission Spectroscopy and Analysis of Dust, Disks, and Regoliths, Vol. 196, p. 77

Neugebauer, G., Soifer, B. T., Beichman, C. A., Aumann, H. H., Chester, T. J., Gautier, T. N., Lonsdale, C. J., Gillett, F. C., Hauser, M. G., \& Houck, J. R. (1984). Early results from the Infrared Astronomical Satellite, Science, Vol. 224, pp. 14-21

Nichols, R. H. (1992). The origin of neon-E: Neon-E in single interstellar silicon carbide and graphite grains, Ph.D. thesis, Washington Univ., Seattle, USA

Nicolussi, G. K., Davis, A. M., Pellin, M. J., Lewis, R. S., Clayton, R. N., \& Amari, S. (1997). Sprocess zirconium in individual presolar silicon carbide grains, Lunar Planet. Sci., Vol. 28, p. 23

Nicolussi, G. K., Pellin, M. J., Lewis, R. S., Davis, A. M., Amari, S., \& Clayton, R. N. (1998). Molybdenum Isotopic Composition of Individual Presolar Silicon Carbide Grains from the Murchison Meteorite, Geochim. Cosmochim. Ac., Vol. 62, pp. 1093-1104

Ninomiya, S., \& Adachi, S. (1994). Optical Constants of 6H SiC Single Crystals, Jpn. J. Appl. Phys., Vol. 33, No. 5A, pp. 2479

Obarich, V. A. (1971). Optical constants of a-SiC $(6 \mathrm{H})$ in the intrinsic absorption region, J. Appl. Spectrosc., Vol. 15, No. 1, pp. 959-961 
Orofino, V., Blanco, A., Mennella, V., Bussoletti, E., Colangeli, L., \& Fonti, S. (1991). Experimental extinction properties of granular mixtures of silicon carbide and amorphous carbon, Astron. Astrophys., Vol. 252, No. 1, pp. 315-319

Ott, U. (2010). The Most Primitive Material in Meteorites, In: Lecture Notes in Physics 815 Astromineralogy (2nd ed.), ed. Th. Henning, pp. 277-311, Springer-Verlag, ISBN 978-3-642-13258-2, Berlin, Heidelberg

Ott, U., \& Merchel, S. (2000). Noble Gases and the Not So Unusual Size of Presolar SiC in Murchison, 31 st Lunar Planet. Sci. Conf., March 13-17, 2000, Houston, Texas, abstract no. 1356

Papoular, R., Cauchetier, M., Begin, S., \& Lecaer, G. (1998). Silicon carbide and the $11.3-\mu \mathrm{m}$ feature, Astron. Astrophys., Vol. 329, pp. 1035-1044

Pégourié, B. (1988). Optical properties of alpha silicon carbide, Astron. Astrophys., Vol. 194, No. 1-2, pp. 335-339

Petalas, J., Logothetidis, S., Gioti, M., \& Janowitz, C. (1998). Optical Properties and Temperature Dependence of the Interband Transitions of 3C- and $6 \mathrm{H}-\mathrm{SiC}$ in the Energy Region 5 to $10 \mathrm{eV}$, Phys. Status Solidi (B), Vol. 209, No. 2, pp. 499-521

Philipp, H. R. (1958). Intrinsic Optical Absorption in Single-Crystal Silicon Carbide, Phys. Rev., Vol. 111, pp. 440

Philipp, H. R., \& Taft, E. A. (1960). Intrinsic Optical Absorption in Single Crystal Silicon Carbide, In: Silicon Carbide, ed. J. R. O'Connor \& J. Smiltens, pp. 366-370, Pergamon, New York

Pitman, K. M., Hofmeister, A. M., Corman, A. B., \& Speck, A. K. (2008). Optical properties of silicon carbide for astrophysical applications, I. New laboratory infrared reflectance spectra and optical constants, Astron. Astrophys., Vol. 483, pp. 661-672

Prombo, C. A., Podosek, F. A., Amari, S., \& Lewis, R. S. (1993). S-process BA isotopic compositions in presolar SiC from the Murchison meteorite, Astrophys. J., Vol. 410, No. 1, pp. 393-399

Rehn, V., Stanford, J. L., Jones, V. O., \& Choyke, W. J. (1976). Proc. 13th Internat. Conf. Physics of Semiconductors, Marves, Rome, 1976, p. 985

Savina, M. R., Davis, A. M., Tripa, C. E., Pellin, M. J., Clayton, R. N., Lewis, R. S., Amari, S., Gallino, R., \& Lugaro, M. (2003) Barium isotopes in individual presolar silicon carbide grains from the Murchison meteorite, Geochim. Cosmochim. Ac., Vol. 67, No. 17, pp. 3201-3214

Skrutskie, M. F., Reber, T. J., Murphy, N. W., \& Weinberg, M. D. (2001). Inferring Milky Way Structure from 2MASS-selected Carbon Stars, Bulletin of the American Astronomical Society, Vol. 33, p. 1437

Sloan, G. C., Little-Marenin, I. R., \& Price, S. D. (1998). The carbon-rich dust sequence Infrared spectral classification of carbon stars, Astron. J., Vol. 115, p. 809

Speck, A. K. (1998). The Mineralogy of Dust Around Evolved Stars, PhD thesis, University College London

Speck, A. K., \& Hofmeister, A. M. (2004). Processing of Presolar Grains around PostAsymptotic Giant Branch Stars: Silicon Carbide as the Carrier of the 21 Micron Feature, Astrophys. J., Vol. 600, No. 2, pp. 986-991

Speck, A. K., Barlow, M. J., \& Skinner, C. J. (1997). The nature of the silicon carbide in carbon star outflows, Mon. Not. R. Astron. Soc., Vol. 288, p. 431 
Speck, A. K., Hofmeister, A. M., \& Barlow, M. J. (1999). The SiC Problem: Astronomical and Meteoritic Evidence, Astrophys. J., Vol. 513, No. 1, pp. L87-L90

Speck, A. K., Thompson, G. D., \& Hofmeister, A. M. (2005). The Effect of Stellar Evolution on SiC Dust Grain Sizes, Astrophys. J., Vol. 634, pp. 426-435

Speck, A. K., Cami, J., Markwick-Kemper, C., Leisenring, J., Szczerba, R., Dijkstra, C., Van Dyk, S., \& Meixner, M. (2006). The Unusual Spitzer Spectrum of the Carbon Star IRAS 04496-6958: A Different Condensation Sequence in the LMC?, Astrophys. J., Vol. 650, pp. 892-900

Speck, A. K., Corman, A. B., Wakeman, K., Wheeler, C. H., \& Thompson, G. (2009). Silicon Carbide Absorption Features: Dust Formation in the Outflows of Extreme Carbon Stars, Astrophys. J., Vol. 691, pp. 1202-1221

Spitzer, W. G., Kleinman, D., \& Frosch, C. J. (1959a). Infrared Properties of Cubic Silicon Carbide Films, Phys. Rev., Vol. 113, pp. 133-136

Spitzer, W. G., Kleinman, D., \& Walsh, D. (1959b). Infrared Properties of Hexagonal Silicon Carbide, Phys. Rev., Vol. 113, pp. 127-132

Srinivasan, S., Sargent, B. A., Matsuura, M., Meixner, M., Kemper, F., Tielens, A. G. G. M., Volk, K., Speck, A. K., Woods, P. M., Gordon, K., Marengo, M., \& Sloan, G. C. (2010). The mass-loss return from evolved stars to the Large Magellanic Cloud. III. Dust properties for carbon-rich asymptotic giant branch stars, Astron. Astrophys., Vol. 524, p. A49

Steffen, M., Szczerba, R., Menshchikov, A., \& Schoenberner, D. (1997). Hydrodynamical models and synthetic spectra of circumstellar dust shells around AGB stars, Astron. Astrophys., Vol. 126, pp. 39-65

Stephens, J.R. (1980). Visible and ultraviolet $(800-130 \mathrm{~nm})$ extinction of vapor-condensed silicate, carbon, and silicon carbide smokes and the interstellar extinction curve, Astrophys. J., Vol. 237, pp. 450-461

Stroud, R. M., Nittler, L. R., \& Hoppe, P. (2004). Microstructures and Isotopic Compositions of Two SiC X Grains, Meteorit. Planet. Sci., Vol. 39, p. 5039

Theodorou, G., Tsegas, G., \& Kaxiras, E. (1999). Theory of electronic and optical properties of 3C-SiC, J. Appl. Phys, Vol. 85, No. 4, pp. 2179- 2184

Thompson, G. D., Corman, A. B., Speck, A. K., \& Dijkstra, C. (2006). Challenging the Carbon Star Dust Condensation Sequence: Anarchist C Stars, Astrophys. J., Vol. 652, p. 1654

Treffers, R., \& Cohen, M. (1974). High-resolution spectra of cool stars in the 10- and 20micron regions, Astrophys. J., Vol. 188, p. 545

Ueta, T., \& Meixner, M. (2003). 2-DUST: A Dust Radiative Transfer Code for an Axisymmetric System, Astrophys. J., Vol. 586, No. 2, pp. 1338-1355

Van Schmus, W. R., \& Wood, J. A. (1967). A chemical-petrologic classification for the chondritic meteorites, Geochim. Cosmochim. Ac., Vol. 31, pp. 747-765

Volk, K., Kwok, S., \& Langill, P. P. (1992). Candidates for extreme carbon stars, Astrophys. J., Vol. 391, p. 285

Volk, K., Kwok, S., \& Hrivnak, B. J. (1999). High-Resolution Infrared Space Observatory Spectroscopy of the Unidentified 21 Micron Feature, Astrophys. J., Vol. 516, No. 2, pp. L99-L102

Volk, K., Xiong, G., \& Kwok, S. (2000). Infrared Space Observatory Spectroscopy of Extreme Carbon Stars, Astrophys. J., Vol. 530, p. 408 
Wheeler, B. (1966). The ultraviolet reflectivity of a and $\beta$ SiC, Solid State Commun., Vol. 4, No. 4, pp. 173-175.

Willacy, K., \& Cherchneff, I. (1998). Silicon and sulphur chemistry in the inner wind of IRC+10216, Astron. Astrophys., Vol. 330, p. 676

Willems, F. J. (1988). IRAS low-resolution spectra of cool carbon stars. II - Stars with thin circumstellar shells. III - Stars with thick circumstellar shells, Astron. Astrophys., Vol. 203, pp. 51-70

Windsteig, W., Dorfi, E. A., Hoefner, S., Hron, J.,\& Kerschbaum, F. (1997). Mid- and farinfrared properties of dynamical models of carbon-rich long-period variables, Astron. Astrophys., Vol. 324, pp. 617-623

Xie, C., Xu, P., Xu, F., Pan, H., \& Li, Y. (2003). First-principles studies of the electronic and optical properties of $6 \mathrm{H}-\mathrm{SiC}$, Physica B, Vol. 336, pp. 284-289

Yin, Q.-Z., Lee, C.-T. A., \& Ott, U. (2006). Signatures of the s-process in presolar silicon carbide grains: Barium through hafnium, Astrophys. J., Vol. 647, pp. 676-684 


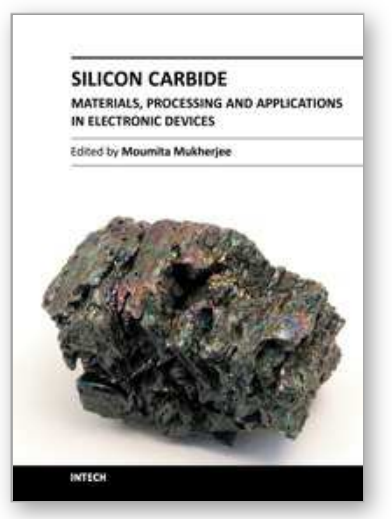

\author{
Silicon Carbide - Materials, Processing and Applications in \\ Electronic Devices \\ Edited by Dr. Moumita Mukherjee
}

ISBN 978-953-307-968-4

Hard cover, 546 pages

Publisher InTech

Published online 10, October, 2011

Published in print edition October, 2011

Silicon Carbide $(\mathrm{SiC})$ and its polytypes, used primarily for grinding and high temperature ceramics, have been a part of human civilization for a long time. The inherent ability of $\mathrm{SiC}$ devices to operate with higher efficiency and lower environmental footprint than silicon-based devices at high temperatures and under high voltages pushes SiC on the verge of becoming the material of choice for high power electronics and optoelectronics. What is more important, $\mathrm{SiC}$ is emerging to become a template for graphene fabrication, and a material for the next generation of sub-32nm semiconductor devices. It is thus increasingly clear that $\mathrm{SiC}$ electronic systems will dominate the new energy and transport technologies of the 21st century. In 21 chapters of the book, special emphasis has been placed on the â€œmaterialsâ€ aspects and developments thereof. To that end, about $70 \%$ of the book addresses the theory, crystal growth, defects, surface and interface properties, characterization, and processing issues pertaining to $\mathrm{SiC}$. The remaining $30 \%$ of the book covers the electronic device aspects of this material. Overall, this book will be valuable as a reference for $\mathrm{SiC}$ researchers for a few years to come. This book prestigiously covers our current understanding of $\mathrm{SiC}$ as a semiconductor material in electronics. The primary target for the book includes students, researchers, material and chemical engineers, semiconductor manufacturers and professionals who are interested in silicon carbide and its continuing progression.

\title{
How to reference
}

In order to correctly reference this scholarly work, feel free to copy and paste the following:

Karly M. Pitman, Angela K. Speck, Anne M. Hofmeister and Adrian B. Corman (2011). Optical Properties and Applications of Silicon Carbide in Astrophysics, Silicon Carbide - Materials, Processing and Applications in Electronic Devices, Dr. Moumita Mukherjee (Ed.), ISBN: 978-953-307-968-4, InTech, Available from: http://www.intechopen.com/books/silicon-carbide-materials-processing-and-applications-in-electronicdevices/optical-properties-and-applications-of-silicon-carbide-in-astrophysics

\section{INTECH}

open science | open minds

\section{InTech Europe}

University Campus STeP Ri

Slavka Krautzeka 83/A

51000 Rijeka, Croatia

Phone: +385 (51) 770447

\section{InTech China}

Unit 405, Office Block, Hotel Equatorial Shanghai

No.65, Yan An Road (West), Shanghai, 200040, China 中国上海市延安西路65号上海国际贵都大饭店办公楼 405 单元 Phone: +86-21-62489820 
Fax: +385 (51) 686166

Fax: +86-21-62489821

www.intechopen.com 
(C) 2011 The Author(s). Licensee IntechOpen. This is an open access article distributed under the terms of the Creative Commons Attribution 3.0 License, which permits unrestricted use, distribution, and reproduction in any medium, provided the original work is properly cited. 